Artigo de ReVISÃo

\title{
Atualização da nomenclatura de espécies do gênero Heliconia (Heliconiaceae)
}

\author{
CARLOS EDUARDO FERREIRA DE CASTRO(1); ANDRÉ MAY(1) ${ }^{(1)}$ CHARLESTON GONÇALVES(2)
}

\begin{abstract}
RESUMO
As helicônias constituem um grupo de plantas cujo cultivo vem se intensificando devido ao crescente mercado. Porém, o uso incorreto da denominação para as espécies que vêm sendo cultivadas tem ocasionado alguns problemas ao produtor, como a decisão sobre adequadas técnicas de cultivo e manejo fitossanitário a serem adotadas, uma vez que o grupo é muito extenso e as exigências de nutrição mineral, espaçamento, condições de cultivo e ocorrência de pragas e doenças variam conforme a espécie considerada. Essa incorreção tem também ocasionado alguns entraves referentes às relações comerciais que envolvem a venda de mudas. Muitas vezes, seguindo nomenclaturas inadequadas ou nomes populares e/ou de variedades, o produtor rural pensa estar adquirindo mudas de determinada espécie, adaptada à sua região de cultivo e recebe um outro produto que poderá não ter uma produção satisfatória, ocorrendo prejuízos. O estudo baseou-se principalmente em informações obtidas em trabalhos originais publicados em periódicos nacionais e internacionais e livros sobre helicônias publicados entre 1880 e 2002 com descrições de espécies de helicônias. A interpretação dos dados compilados permitiu estipular 176 espécies de helicônias, de ocorrência na região neotropical e seis espécies nas Ilhas do Pacífico, perfazendo 182 espécies. O maior número de espécies e subespécies descritas tem ocorrência natural na Colômbia (94), seguindo em ordem decrescente Equador (60) Panamá (56), Costa Rica (47), Brasil (37), Peru (32), Venezuela (26), Nicarágua (22), Guatemala (16), Bolívia (15), Honduras e México (14) e Suriname (13). Das 182 espécies elencadas, 94 são registradas como endêmicas de determinada região, o que aponta uma grande fragilidade do gênero com relação à conservação de germoplasma. Face ao elevado grau de endemismo recomenda-se urgência no estabelecimento de um programa nacional/internacional que vise à coleta e manutenção de germoplasma de espécies do gênero.
\end{abstract}

Palavras-chave: helicônias, espécies, endemismo, floricultura tropical, Zingiberales.

\section{ABSTRACT \\ Nomenclature Review of Species of Heliconia Genus}

Heliconias are a group of plants whose cultivation for cut flowers has grown in importance. Different cultural requirements for different species make it essential that growers know what species they are buying and growing. Incorrect naming for the cultivated species poses a problem for growers who do not know what species they are buying and growing. The situation is also confusing when local and foreign names are used or translated into another language. That has also caused some trouble in trade relations with regard to the sale of plants, as rural growers, based on incorrect naming, and/or popular names for the varieties, frequently buy a certain species adapted to their region, but receive a different one, which may not give a satisfactory yield, thus leading to loss. Correct identification of the species is only a start as there are also interspecific hybrids that intergrade in characteristics, making assignment of a species epithet difficult. Our nomenclatural study was based mainly on information obtained from published articles on heliconias in national and international periodicals, as well as from books, published between 1900 and 2002, which described heliconia species. Analysis of the collected data allowed us to establish 176 species of heliconias occurring in the neotropical region, and 6 species on the Pacific Islands, totaling 182 known species. Nearly half of the species described are found in Colombia (94), and in decreasing order, as follows: Ecuador (60) Panama (56), Costa Rica (47), Brazil (37), Peru (32), Venezuela (26), Nicaragua (22), Guatemala (16), Bolivia (15), Honduras and México (14) and Suriname (13). Ninety-four of these 182 species are endemic to certain regions, what indicates the great fragility of the genus in preserving germplasm. On account of the high level of endemism, it is of pressing importance to define a national/ international program aimed at the collection and conservation of species germplasm under that genus.

Key words: heliconia, species, endemism, tropical floriculture, Zingiberales

\section{INTRODUÇÃO}

O cultivo de helicônias, plantas que constituem o gênero Heliconia (L.) L., tem tido expressivo crescimento nos últimos anos, consolidando um promissor mercado para o produtor nacional de flores e plantas ornamentais, com algumas espécies sendo cultivadas de forma intensiva para atender o mercado de flores de corte ou plantas para jardins.

Originalmente incluído na família Musaceae, o gênero Heliconia, em função de suas características próprias de individualização, passou, segundo proposição de NAKAI (1941), a constituir a família Heliconiaceae como único representante, interpretação endossada por outros autores como CRONQUIST (1981) e TOMLINSON $(1959,1962)$.

A primeira descrição botânica de espécies de Heliconia, conforme KRESS (1984), é de Plumier, em 1703. É uma descrição suscinta e genérica do gênero Bihai, denominação inicial do gênero Heliconia, e polinômios para três variações: Bihai amplissimis foliís, florum vasculis coccineis; Bihai amplissimis foliis, florum vasculis subnigris; e Bihai amplissimis foliis, florum vasculis variegatis Essas três variedades foram incluidas por Lineu, em 1763, em uma só espécie, Musa bihai, sendo

\footnotetext{
(1) Instituto Agronômico - Centro de Horticultura/IAC/APTA (SP) - Caixa Postal 28, 13.012-970, Campinas (SP), e-mails: ccastro@iac.sp.gov.bre amay@iac.sp.gov.br.

(2) Pólo Regional de Desenvolvimento Tecnológico dos Agronegócios do Leste Paulista/DDD/APTA - Caixa Postal 1, 13.910-000, Monte Alegre do Sul (SP), e-mail: charleston@aptaregional.sp.gov.br
} 
mantidas as diagnoses de Plumier. Posteriormente, em 1771, Lineu descreveu o gênero Heliconia designando como tipo a $H$. bihai caracterizada pelas brácteas vermelhas e flores amarelas.

As helicônias podem ser resumidamente descritas, segundo CASTRO (1995), como plantas herbáceas rizomatosas, com folhas dísticas, grandes de até cinco metros de comprimento, simples, inteiras, com uma base envolvente formando um pseudocaule. A inflorescência é terminal, formada por numerosas espatas grandes, geralmente de cores fortes, dispostas disticamente ou espiraladas ao longo de um eixo central. As espatas encerram de duas até muitas flores. As flores perfeitas são marcadamente zigomorfas subtendidas por uma bráctea. $\mathrm{O}$ androceu é formado por cinco estames férteis e um estaminódio. O ovário contém um óvulo subbasal simples em cada lóculo. O fruto é do tipo baga com uma a três sementes não ariladas.

O nome genérico mais antigo foi reconhecido por GRIGGS (1904) que transferiu todas as espécies conhecidas de Heliconia para o gênero Bihai Adanson. Contudo, no Congresso Internacional de Botânica, realizado em Viena em 1905, o gênero Heliconia foi reinstaurado como nomen conservandum \{FARR et al., 1979).

No final do século XIX foram feitas revisões e resumos do gênero, sendo listadas várias espécies, 43 por PETERSEN (1890) na Flora Brasiliensis e 25 por KUNTZE (1891). Na relação de Petersen, contudo, existem 14 sinonímias atualmente aceitas. A primeira classificação infragenérica do gênero é de BAKER (1893), que fez descrições e chaves para 29 espécies. A mais ampla descrição do gênero, no início do século passado foi a de GRIGGS (1915) que reconheceu 48 espécies neotropicais e continha uma classificação infragenérica.

Nenhuma outra revisão do gênero foi então completamente feita. Durante os últimos 90 anos, muitas espécies têm sido descritas e vários tratamentos florísticos regionais têm ajudado a aumentar o conhecimento da variação e da diversidade de Heliconia. Tendo como base material de herbários e observações de campo, foram feitas revisões das espécies relacionadas com $H$. bihai - sect. Heliconia (ANDERSSON, 1981), das espécies dos subgêneros Taeniostrobus e Heliconia (ANDERSSON, 1992), das helicônias da América Central com inflorescências pendentes (KRESS 1984), das espécies do subgênero Stenochlamys (ANDERSSON, 1985a) e das espécies do subgênero Heliconiopsis (KRESS, 1990). Essas revisões têm resolvido muitos problemas taxonômicos e de nomenclatura desses grupos.

Estudos sobre floras regionais são disponíveis para helicônias da Guatemala (STANDLEY e STEYERMARK, 1952); Costa Rica (STANDLEY, 1937, STILES, 1975, 1980, 1982, DANIELS e STILES, 1979); Panamá(WOODSON eSCHERY, 1945; KRESS 1981a, 1986, 1991), América Central (STANDLEY, 1927, SMITH, 1975); México (BAÉZ, 1987); Venezuela (RODRIGUEZ, 1954, ARISTEGUIETA, 1961); Peru (MACBRIDE, 1931, 1936, PLOWMAN et al. 1982); Nicarágua (SMITH, 1977, 1980); Colômbia (ABALO e MORALES, 1982, 1983ab, 1984; MORALES 1984); Equador (DIELS, 1937; DODSON e
GENTRY, 1978, ABALO e MORALES, 1985); Brasil (HUBER, 1906; BARREIROS, 1971, 1974, 1976, 1978, 1979, 1980, 1985, 1992; BURLE MARX, 1974; EMYGDIO, 1975, 1976, MELLO FILHO, 1975, MELLO FILHO e SANTOS, 1976, 1977, 1983, 1987) e SANTOS, 1978); e Ilhas do Pacífico (SMITH 1967, 1989; KRESS 1990), mas a maioria dos estudos está incompleto, embora tenha acrescentado à lista de helicônias muitas e novas espécies. Paralelamente, na década de 1980, foram feitas as revisões das diversas seções em que se subdividem o gênero Heliconia, promovendo-se então a aglutinação de muitas espécies descritas anteriormente e estabelecendo-se as sinonímias respectivas (ANDERSSON 1981, 1985ab). Entretanto KRESS (1989, 1990, 1997, 1999) contesta algumas das espécies e sinonímias reconhecidas por esse autor.

Desse modo, o número de espécies consideradas para o gênero Heliconia é motivo de controvérsias entre diferentes autores. Existem 257 espécies registradas no Index Kewensis entre 1895 e 2000. Alguns autores aceitam cerca de 120 espécies (ANDERSSON, 1981, 1985ab, 1989), enquanto para outros o número de espécies está entre 150 e 250 (SANTOS 1978, ABALO e MORALES, 1982, 1983ab, ARISTEGUIETA 1961, KRESS, 1981, 1984, 1986, 1989, 1990 e WATSON e SMITH 1979), A definição do número de espécies ainda é difícil, pois rotineiramente novas espécies têm sido descritas, e outras, a cada revisão do gênero ou subgêneros, têm sido incluídas em sinonímias. Estas representam um número considerável, e também para as sinonímias existem controvérsias entre autores.

Mantendo as três taxas de GRIGGS (1903), ANDERSSON (1981, 1985ab) subdividiram o gênero em quatro subgêneros: (1) Taeniostrobus (Kuntze) Griggs, um grupo com brácteas amplas; (2) Stenochlamys Baker, com brácteas estreitas; (3) Heliconia (Platychlamys Baker), no qual foram mantidas espécies de relações incertas; e (4) Pendulae Griggs, um grupo com inflorescências pendentes. As seções adicionalmente definidas dentro destas foram fundamentadas na consistência das estruturas vegetativas e forma do estaminódio e do estilo, em desacordo com os agrupamentos de KRESS (1984), especialmente de helicônias pendentes. A monografia de Kress de 1984 expressa a opinião de que heliconias pendentes não são necessariamente monofiléticas. KRESS (1990) assinalou as espécies das ilhas do Pacífico como no subgênero Heliconiopsis, um taxon também com precedência anterior.

Face aos conhecimentos atuais, as diversas espécies de Heliconia podem então, ser subdivididas em cinco subgêneros. Para essa classificação a proposta mais recente é de KRESS et al. (1993), que considera o subgenêro Heliconia com as seções Heliconia, Episcopales, Tortex, Farinosae, Complanatae e Tenebria, o subgênero Taeniostrobus; o subgênero Stenochlamys com as seções Lanea, Stenochlamys, Proximochlamys, Lasia, Cannastrum e Zingiberastrum; e o subgênero Griggsia com as seções Griggsia. Barbatae, Arcuatae, Longae, Obscurae, Dromedarius, Sigmoideae, Rostratae, Pendulae, Retiformes e Contortex. A esses deve ser acrescentado o subgênero Heliconiopsis (KRESS, 1990) que inclui as espécies das ilhas do Oceano Pacífico. 
A publicação "Heliconia, An Identification Guide”, de BERRY e KRESS (1991) não soluciona divergências taxonômicas, mas é uma referência conveniente para a identificação visual de muitas das espécies cultivadas, variedades botânicas e alguns cultivares tanto do Novo Mundo como do Pacífico Tropical. Nesse livro, as chaves de classificação foram substituídas por fotografias coloridas que facilitam a identificação.

O uso de incorreta denominação para as espécies que vêm sendo cultivadas e o desconhecimento das sinonímias podem ocasionar problemas. Alguns destes correlatos à decisão do produtor sobre adequadas técnicas de cultivo e manejo fitossanitário a serem adotadas, uma vez que o grupo é muito extenso e as exigências de nutrição mineral, espaçamento, condições de cultivo e ocorrência de pragas e doenças variam conforme a espécie considerada. Também podem ocorrer alguns entraves nas relações comerciais que envolvem venda de mudas, pois, muitas vezes, guiando-se por nomenclaturas inadequadas ou nomes populares e/ou de variedades, o produtor rural pensa estar adquirindo mudas de determinada espécie adaptadas à sua região de cultivo e recebe uma outra espécie que poderá não oferecer uma produção típica da helicônia adquirida, ocasionando prejuízos. Outros problemas se referem ao contexto do conhecimento técnico-científico, uma vez que o uso de nomenclatura inadequada pode contribuir para disponibilização de informações incorretas e mesmo para perpetuação de erros.

Tendo em vista a importância econômica que as helicônias vêm assumindo, foi objetivo deste trabalho, disponibilizar uma relação atualizada das espécies que compõem o gênero Heliconia. Para tanto foram relacionadas as espécies atualmente validadas como tal e elencadas as sinonímias estabelecidas para cada espécie, conforme a subdivisão vigente. Adicionalmente é indicada a região de ocorrência natural e as principais variedades existentes no comércio para cada espécie.

\section{MATERIALEMÉTODOS}

O estudo foi iniciado com a compilação de informações sobre Heliconia registradas no Index Kewensis, período 1895-2000, resultando em uma listagem de todas as espécies arroladas na publicação. Posteriormente, conforme as citações desta publicação, reuniram-se os trabalhos publicados em periódicos nacionais e internacionais e livros sobre helicônias publicados entre 1870 e 2002 com as descrições originais das espécies do gênero. Desses trabalhos foram extraídaos a descrição das espécies, a sinonímia relatada e os locais onde os autores efetuaram coletas, permitindo assim a identificação de regiões de ocorrência natural.

Foram também obtidas informações sobre os subgêneros e seções em que se distribuem as espécies de helicônias, utilizando como fonte as revisões de ANDERSSON (1981, 1985ab, 1992) e os trabalhos de KRESS $(1984,1990)$ e KRESS et al. (1993).

As sinonímias foram compiladas de vários artigos, mas principalmente das revisões dos subgêneros já citadas e outros como BARREIROS (1972), ABALO e MORALES (1982, 1983a) e SANTOS (1978).

As informações sobre variedades comerciais foram extraídas de livros, catálogos de produtores, boletins de sociedades e propagandas, bem como acionado o Registro de Variedades da Heliconia Society.

Finalizada a fase de compilação de informações, as espécies foram listadas alfabeticamente, dentro de cada subgênero e seção, produzindo tabelas que indicam a espécie, a publicação que foi encontrada a descrição original da espécie, a sinonímia proposta, os locais de ocorrência natural e as variedades reconhecidas como tal.

Adicionalmente, foram relacionadas espécies sobre as quais existem dúvidas de se caracterizarem como táxon válido, bem como os híbridos naturais já caracterizados.

\section{RESULTADOS E DISCUSSÃO}

As consultas ao Index Kewensis, no período de 1995 a 2000, permitiram elencar 257 taxons de helicônias. Estes reavaliados com o apoio de outros trabalhos sobre espécies e revisões sobre o gênero propiciaram nova organização. Desse modo, nas tabelas 1 a 5 são estabelecidas, respeitando-se os subgêneros e seções respectivas de cada espécie, a relação de espécies aceitas, a referência da descrição original, a sinonímia relatada a cada uma, a região de ocorrência natural e as variedades comerciais.

$\mathrm{Na}$ tabela 1, que se refere ao subgênero Taeniostrobus são incluídas quatro espécies, todas de ocorrência natural na América Central e sobre as quais não existem divergências de classificação pelos taxonomistas.

O subgênero Heliconia, relacionado na tabela 2, compreende 45 espécies, distribuídas nas Seções Episcopales (1 espécie), Heliconia (10 espécies), Tortex (17 espécies), Tenebria (2 espécies), Farinosae (12 espécies) e Complanatae (3 espécies). As Seções Episcopales, Tenebria e Complanatae compreendem apenas espécies com distribuição sul-americana. Todas as espécies da Seção Complanatae são endêmicas de determinadas regiões, da Colômbia ou Equador. As demais Seções têm espécies com ampla distribuição pelo trópico americano com endemismo para duas espécies da Seção Heliconia, nove espécies em Tortex e oito em Farinosae.

Na Seção Farinosae estão reunidas algumas das principais espécies de ocorrência natural do Brasil, as $H$. farinosae, $H$. sampaioana, $H$. velloziana e $H$. kautzikiana, sendo as três primeiras muitas vezes encontradas no comércio, nos Estados do Rio de Janeiro e de São Paulo.

Nesse subgênero são encontradas várias divergências entre os taxonomistas com relação à aceitação como espécie ou como sinonímia.

ANDERSSON (1981) coloca a H. aurea como sinonímia de $H$. bihai, o que não é aceito por KRESS (1984), KRESS (1997) e KRESS et al. (1999). ANDERSSON (1981) justifica que a $H$. aurea descrita por RODRIGUES (1954) é apenas uma forma mais vigorosa de $H$. bihai, com maior altura, camada cerosa nos pecíolos e coloração diversa das brácteas, características que considera 
insignificantes para a separação de espécies. KRESS (1984), KRESS (1997) e KRESS et al. (1999), entretanto, sustentam que outras características como a posição da raque levemente flexionada e a ausência de sépalas hirsutas em $H$. aurea, bem como as informações de ARISTEGUIETA (1961) dessa espécie ter brácteas com maior dimensão e forma dista, são suficientes para separálas.

Também existem divergências entre as $H$. bourgaeana e $H$. champneiana uma vez que ANDERSSON (1981) considera $H$. champneiana como sinonímia da primeira. KRESS (1991), entretanto, as consideram espécies distintas.

A $H$. bourgaeana, segundo ANDERSSON (1981) tem como características as brácteas profundamente cimbiformes, de coloração amarelo-intensa na base, algumas vezes tingidas de vermelho mas não com variegação zonal, por suas sépalas densamente vilosas ventralmente e pela forma do estaminódio, acentuadamente convexo, quase retangular e com ápice longo-caudado. Já a H. champneiana, conforme descrição original em GRIGGS (1903), tem brácteas uniformes na forma e tamanho, largamente ovada e de coloração amarela ou alaranjada brilhantes e com pontuações vermelhas ou vermelho-escuras distribuídas por toda a bráctea, mas principalmente concentradas na base. Face a essas diferenças opta-se por considerá-lás espécies distintas.

Existem dúvidas sobre $H$. farinosa, $H$. sampaioana e $H$. velloziana. ANDERSSON (1992) as reduz a sinonímias, prevalecendo como espécie a $H$. farinosa, caracterizada por brácteas conspicuamente curvadas no ápice, flores semi-expostas na antese, perianto fortemente angular, proximal parabólico e torcido na maturidade e estaminódio semelhante a uma escama sem ápice bem definido. Segundo esse autor, na sua região de ocorrência natural, no sudeste do Brasil, a espécie é bastante homogênea correspondendo a $H$. velloziana, que só se diferencia por ser mais vigorosa com folhas e inflorescências de maior tamanho, uma camada cerosa na face inferior das folhas e inflorescências mais ou menos glabras. Também tem muitos morfotipos, alguns com cinco a oito brácteas e um ângulo agudo de aproximadamente trinta e cinco graus de inserção com o eixo da inflorescência. Outros têm lâminas foliares com camada cerosa na face inferior e inflorescências com pilosidade.

O autor também comenta que a $H$. farinosa é, no senso estrito definido por EMYGDIO (1976) e SANTOS (1978), caracterizada por pequena estatura, lâminas foliares com camada cerosa e inflorescências glabras, enquanto que a H. sampaiona compreende plantas maiores, com lâminas foliares com camada cerosa e inflorescências pilosas.

Face a essas descrições e mesmo reconhecendo ter tido acesso a pouco material herbarizado proveniente de populações naturais, ANDERSSON (1992) as considera como sinonímias. Outros autores como CRILEY e BROSCHAT (1992) e KRESS (1992) não fazem essa distinção. Recorrendo ao trabalho de SANTOS (1978) observa-se a existência de muitas características diferentes entre elas principalmente no formato das folhas, pilosidade, tamanho de inflorescência, tamanho e pilosidade de pedúnculo, número e pilosidade de brácteas por inflorescência, bráctea inferior foliosa ou não, cor, forma, comprimento e pilosidade de bractéolas, forma de estaminódio, cor e pilosidade de ovário e forma e dimensões do pólen. Desse modo, opta-se por mantê-las individualizadas como espécies.

Outras espécies, que suscitam divergências são as $H$. wagneriana e H. lennartiana. ANDERSSON (1992), com algumas dúvidas, incluiu a $H$. lennartiana como sinonímia de $H$. wagneriana, sugerindo ser a primeira um morfotipo da segunda ocorrente em altitudes mais elevadas. Mas assinala ter analisado uma amostra muito pequena e pouco representativa de $H$. lennartiana, mas da qual pode presumir, que esta, de fato, possa merecer um tatamento específico. Para KRESS (1986) a $H$. lennartiana é muito próxima de $H$. wagneriana, mas desta difere pela forma das inflorescências, pêlos nas sépalas ventrais, cor e forma do perianto na antese, forma e ponto de inserção do estaminódio no tubo da corola e número de flores nas brácteas cincinais. Como semelhança entre espécies indica o ápice do perianto de coloração verdeescura. Opta-se, portanto, pelas diferenças estabelecidas e própria incerteza de ANDERSSON (1992) em reconhecêla como espécie válida.

Existem ainda divergências com relação as $H$. lindsayana e $H$. sarapiquensis, espécies incluídas na Seção Tortex. A H. lindsayana, segundo KRESS (1986) compartilha muitas características com a $H$. sarapiquensis, mas dela difere por brácteas cincinais rosadas, pecíolos de coloração vinho opaco e lâminas foliares de cor verdebrilhante na superfície superior e glauca na face inferior próximo as nervuras e com uma distinta nervura central de cor branca. ANDERSSON (1992), por outro lado, considera que cor e cerosidade das lâminas foliares não são caracteres suficientes para a distinção de espécies, decidindo por colocar $H$. lindsayana como sinônimo de $H$. sarapiquenses. Contudo, assinala que não teve acesso a material suficiente de $H$. lindsayana para um melhor julgamento. Desse modo, face à inexistência de comprovações mais apuradas, decide-se, neste trabalho, em mantê-las como espécies diferentes.

O subgênero Stenochlamys compreende 47 espécies, distribuídas nas Seções Lanea (18 espécies), Stenochlamys (6 espécies), Proximochlamys (1 espécie), Lasia (5 espécies), Cannastrum (9 espécies) e Zingiberastrum (8 espécies), conforme tabela 3. As Seções Proximochlamys e Lasia compreendem apenas espécies com distribuição sul-americana. Em Lasia observa-se uma espécie endêmica da Colômbia As demais Seções têm espécies com ampla distribuição pelo trópico americano com endemismo para nove espécies da Seção Lanea, sendo oito sul-americanas e uma centro-americana, uma espécie e uma subespécie, ambas sul-americanas espécies em Stenochlamys, quatro espécies sul-americanas em Cannastrum e uma espécie centro-americana em Zingiberastrum.

Nesse subgênero, as principais divergências de nomenclatura são encontradas nas Seções Lanea, com relação a $H$. meridensis e $H$. mincana e na Seção Cannastrum entre $H$. mettalica e H. osaensis var. rubescens.

A $H$. meridensis é caracterizada por ANDERSSON (1985a) por flores amarelas retas ou quase retas, pequeno 
estaminódio em forma de gancho e indumento flocoso de coloração marrom na raque e nas brácteas. Comparando essa espécie com a $H$. mincana a partir das descrições de ambas, o autor observou a existência de muitos caracteres de diagnose iguais, como a inflorescência espiralada pubescente, inflorescências amarelas de 45 a $50 \mathrm{~cm}$ de comprimento e pequeno estaminódio. CRILEY e BROSCHAT (1992) e KRESS et al. (1999), entretanto as considera espécies distintas, validando o estabelecido por ABALO e MORALES (1983a).

Na outra divergência encontrada, a $H$. osaensis var. rubescens foi considerada nova variedade botânica por STILES (1980) em um acréscimo aos estudos de DANIELS e STILES (1979) sobre as helicônias da Costa Rica. O autor caracterizou a variedade por flores vermelhas a vermelhoescuras com nuances de alaranjado, pubescência de cor marrom na inflorescência, ovário jovem rosado claro com ápice negro e lâminas foliares verde-escuras em contraste à nervura central de coloração mais clara.

ANDERSSON (1985a), entretanto, a coloca como sinonímia de $H$. mettalica, porém, sem, estabelecer suas similaridades. Em sua revisão caracteriza a $H$. mettalica por seu rico indumento flocoso nas bainhas foliares, inflorescências com perianto vermelho e estaminódio pequeno. Desse modo, em não havendo maiores comprovações de similaridade opta-se em mantê-las como espécies distintas.

Ainda nesse subgênero, uma espécie que tem suscitado dúvidas e tratamentos diversos é a $H$. angusta, espécie endêmica da região sudeste do Brasil, com inúmeras formas descritas e sinonímias elencadas. A revisão de ANDERSSON (1985) estabelece, entretanto, a $H$. angusta, como um complexo polimórfico, em que as variações entre as espécies descritas como tal, por MELLO FILHO e SANTOS (1976), SANTOS (1978) e BARREIROS (1969) apresentam poucas diferenças de cor de espatas, pedicelo e ovário, com relação à espécie tipo. Devem, portanto, ser mantidas as sinonímias recomendadas.

O subgênero Heliconiopsis, conforme tabela 4, compreende apenas seis espécies todas originárias de Ilhas do Pacífico como lhas Molucas, Ilhas Salomão, PapuaNova Guiné, Indonésia, Nova Caledônia, Samoa, Vanatu e Sulawesi e com certo grau de endemismo. Entre as espécies que compõem o subgênero não existem controvérsias taxonômicas, apesar de grande número de sinonímias para a $H$. indica e suas variedades botânicas.

O subgênero Griggsia, conforme a compilação na tabela 5, é o maior em número de espécies, 80 no total, todas com inflorescências pendentes e distribuídas nas Seções Griggsia (5 espécies), Barbatae (12 espécies), Longae (5 espécies), Pendulae (9 espécies), Rostratae (6 espécies), Sigmoideae (17 espécies), Obscurae (14 espécies), Contortex (2 espécies), Arcutae (2 espécies), Dromedarius (4 espécies) e Retiformes (4 espécies). As Seções Griggsia, Obscurae, Dromedarius e Retiformes compreendem apenas espécies com distribuição sulamericana. Em Griggsia observa-se endemismo em quatro espécies, duas colombianas e duas equatorianas. Onze espécies são endêmicas em Obscurae, as quatro em Dromedaruis, todas da Colômbia e três espécies em
Retiformes As demais Seções têm espécies com ampla distribuição pelo trópico americano com endemismo para sete espécies e uma subespécie da Seção Barbatae, duas espécies, ambas equatorianas em Longae, quatro espécies sul-americanas em Pendulae e doze espécies em Sigmoideae.

ANDERSSON (1985b) relata que KRESS (1984) aplicou o nome $H$. curtispatha a um outro taxon, que é reconhecido como $H$. longa. A sinonímia elencada, portanto, não deve ser considerada.

Na revisão efetuada, foram encontradas descrições de outras onze espécies, que não apareceram em trabalhos de floras regionais, revisões sobre o gênero e não são consideradas como sinonímias por nenhum autor. Essas espécies estão relacionadas na tabela 6 e, são consideradas neste trabalho como duvidosas.

Também, conforme tabela 7, puderam ser atualmente identificados 23 híbridos naturais de helicônia. Alguns híbridos reúnem muitas das principais variedades comercializadas no mundo.

O híbrido $H$. episcopalis $X$ rostrata referido por ANDERSSON (1985b) é reconhecido como a espécie $H$. flabellata, por ABALO e MORALES (1983a), denominação sustentada por CRILEY e BROSCHAT (1992) e KRESS et al. (1999).

Outro híbrito citado por ANDERSSON (1992) a $H$. latispatha $X$ spathocircinata é descrito por ABALO e MORALES (1985) como $H$. antioquiensis e aceita como tal.

\section{CONCLUSÕES}

A interpretação das informações obtidas permite estipular 176 espécies de helicônias, de ocorrência na região neotropical e seis espécies nas Ilhas do Pacífico, perfazendo 182 espécies válidas, distribuídas em 5 subgêneros e 23 seções. O maior número de espécies e subespécies descritas tem ocorrência na Colômbia (94), seguindo-se em ordem decrescente Equador (60) Panamá (56), Costa Rica (47), Brasil (37), Peru (32), Venezuela (26), Nicarágua (22), Guatemala (16), Bolívia (15), Honduras e México (14) e Suriname (13). O grande número de espécies na América do Sul confirma a região como um dos centros de diversificação do gênero.

Das 182 espécies elencadas, 94 são apontadas como endêmicas de determinada região, o que mostra uma grande fragilidade do gênero com relação à conservação de germoplasma. O maior grau de endemismo ocorre na Colômbia com 36 espécies. Seguem-se Equador (21), Panamá (13), Costa Rica (8), Brasil (6), Peru (5), México (3) e Guatemala, Ilhas Salomão, Samoa, Fiji e Venezuela, cada um com uma espécie endêmica. Recomenda-se, portanto, a implantação de uma política pública no Brasil, visando à implantação e manutenção de banco de germoplasma de helicônias, coordenada pelas agências de fomento à pesquisa e apoiadas por Ministérios, cujo raio de ação sejam convergentes para o desenvolvimento socioeconômico, a ciência e tecnologia e a preservação ambiental. Essa política pública deve ser apoiada em parcerias internacionais para ampliar as possibilidades de intercâmbios. 
Caso, no futuro as espécies relacionadas como duvidosas sejam validadas, o número de espécies aceitas no gênero Heliconia poderá ser de 193.

\section{REFERÊNCIAS}

ABALO, J. E.; MORALES, L. G. Diez 10) heliconias nuevas de Colômbia. Phytologia, Huntsville, v.54, n.6, p. 411-433, 1983b.

ABALO, J. E. ; MORALES, L. G. Doce (12) heliconias nuevas del Ecuador. Phytologia, Huntsville, v. 52, n.6, p. 387-433, 1983a.

ABALO, J. E. ; MORALES, L. G. Una heliconia nueva de Colombia. Phytologia, Huntsville, v. 55, n.1, p.14-16, 1984.

ABALO, J. E.; MORALES, L. G. Veinticinco (25) heliconias nuevas de Colômbia. Phytologia, Huntsville, v. 51, n.1, p.1-61, 1982.

ABALO, J. E.; MORALES, L. G. Siete (7) heliconias nuevas de Colômbia. Phytologia, Huntsville, v. 57, n.1, p.42-57, 1985.

ABALO, J. E. ; MORALES, L. G. Heliconias de Ecuador. Bol. Soc. Venezol. Cienc. Nat. Quito, v.44, n.147, p.140164, 1991.

ANDERSSON, L. Revision of Heliconia subgen. Stenochlamys (Musaceae- Heliconioideae. Opera Bot. Copenhagen, v.82, p. 1-123, 1985a.

ANDERSSON, L. Musaceae.In: Harling, G. ; Sparre, B.(eds). Flora of Ecuador, Goteborg, v.22, p.1-86, 1985 b.

ANDERSSON, L. Revision of Heliconia sect. Heliconia (Musaceae). Nord. J. Bot. Copenhagen, v.1, n.6, p. 759786, 1981.

ANDERSSON, L. Revision of Heliconia subgen. Taeniostrobus and subgen. Heliconia (MusaceaeHeliconioideae). Opera Bot. Copenhagen, v.111, n.1 p.198, 1992.

ANDERSSON, L. An evolutionary scenario for the genus Heliconia. In: HOLM-NIELSEN, L.B. NIELSEN ; BALSLEV, H. (eds). Tropical Foresta, Botanical Dynamics, Speciation and Diversity, London, 1989, p.173-184..

ARISTEGUIETA, L. Novedades del Gênero Heliconia en Venezuela. Bol. Soc.

Quito, v.22, p.17-24, 1961.

BÁEZ, C. G. Heliconia de Mexico. Biótica, Vera Cruz, v.12, n.2, p.149, 1987.

BAKER,.J.G. A synopsis of the genera and species of Museae. Ann. Bot., London, v.7, p.189-222, 1893.

BARREIROS, H.S. Notas sobre uma nova espécie do gênero Heliconia (Musaceae). Atas Soc. Biol. , Rio de Janeiro, v.12, p.261-263, 1969.

BARREIROS, H. S.. Una nova especie de Heliconia L. (Musaceae) de le raque pendula. Rodriguésia , Rio de Janeiro, v.23, n.38, p.127-130, 1971.

BARREIROS, H. S. Heliconia nova brasiliana et varietas. Morfologia e ecologia -dispersão e polinização (Heliconiaceae (End.) Nakai). Rev. Bras. Biol., Rio de Janeiro, v.32, n.2, p.205-208, 1972.

BARREIROS, H.S. Espécies críticas de Heliconia (Heliconiaceae). III. Com duas espécies brasileiras sendo uma nova. Bradea, Rio de Janeiro, v.1, n.46., p. 459-464, 1974.
BARREIROS, H.S. Heliconiae novae Americanae (Heliconiaceae). Rodriguesia, Rio de Janeiro, v. 41, n.28, p.129-135, 1976.

BARREIROS, H. S. Heliconia bahiensis Barreiros n. sp. (Heliconiaceae). Rodriguesia, Rio de Janeiro, v.29, p.225227, 1978.

BARREIROS, H. S. Arquitetura de Heliconia L. Neotenia (Heliconiaceae). Arquivos do Jardim Botânico, Rio de Janeiro, v.23, p.97-104, 1979.

BARREIROS, H. S. Helicônias novas do Norte e Nordeste do Brasil (Heliconiaceae). Bradea, Rio de Janeiro, v.111, n.3, p.101-104, 1980.

BARREIROS, H.S. Heliconiae novae. Bol. Mus. Bot. Kuhlmann, Belém, v.8, n.1, p.6, 1985.

BARREIROS, H.S Heliconia luciae Barreiros n. sp. (Heliconiaceae). Bol. Mus. Paraense Emilio Goeldi. Ser. Bot. Belém, v.8, n.1, p.157, 1992.

BERRY, F.;.KRESS, W.J. Heliconia: an identification guide. Washington: Smithsonian Institution Press, 1991.

BURLE-MARX, R. Heliconiae novae brasiliensis II. Sobre uma nova espécie de Heliconia L. (Musaceae).

Bradea, Rio de Janeiro, v.1, n.38, p. 379-382, 1974.

CASTRO, C. E. F. Cultivo de Helicônias para exportação .FRUPEX, Brasilia, 1995, 42p.

CRILEY, R.A.; BROSCHAT, T. K. Heliconia: Botany and Horticulture of a New Floral Crop. Horticultural Reviews, New York, v.14, p.1-95 1992.

CRONQUIST, A.. An integrated system of classification of flowering plants. New York: Columbia Univ. Press, 1981. DANIELS, G. S.; STILES, F. G. The Heliconia taxa of Costa Rica. Keys and descriptions. Brenesia, Rio de Janeiro, v.15, (supl.), p.1-150, 1979.

DIELS, L. Beiträge zur Kenninis der Vegetation und Flora von Ecuador. Biblioth. Bot. Berlim, v.116, p.1-190, 1937.

DODSON, C.H. ; GENTRY, A.H. Heliconias (Musaceae) of the Rio Palenque Science Center, Ecuador. Selbyana, Sarasota, v.2, n.2/3, p.291-299, 1978.

EMYGDIO, L. de MELLO FILHO. O gênero Heliconia na flora fluminensis de Frei José Mariano da Conceição Vellozo. Revista Brasil. Biol. Rio de Janeiro, v.35, n.2, p.331-337, 1975.

EMYGDIO, L. de MELLO FILHO. Heliconiae novae Brasiliensis. III. Bradea, Rio de Janeiro, v.11, n.15, p. 9194, 1976

FARR, E. R., J. A. LEUSSINK, ; F. A. STAFLEU. Index nominum genericorum. Utrecht: Bohn, Scheltema \& Holkema, 1979. v.1.

GRIGGS, R. F. On some species of Heliconia. Bull. Torrey

Bot. Club. New York, v.30, n.12, p. 641-664, 1903.

GRIGGS, R. F. Two new species of American wild bananas with a revision of the generic name. Bull. Torrey Bot. Club, New York, v.31, n.3, p.445-447, 1904.

GRIGGS, R. F. Some new species and varieties of Bihai. Bull. Torrey Bot. Club, New York, v.42, n.6, p.315-330, 1915.

HUBER, J. Materiaes para la Flora Amazônica VI. Bol. Museu Goeldi Hist. Nat. Ethnogr., Belém, v.4, p. 510-619, 1906.

KRESS, W. J. New Central American Taxa of Heliconia (Heliconiaceae). Journal of the Arnold Arboretum. Harvard, v.62, n.2, p.243-260, 1981. 
KRESS, W.J. Systematics of Central American Heliconia (Heliconiaceae) with pendant inflorescences. J. Arnold Arbor. Harvard, v.65, n.4 , p.429-532, 1984.

KRESS, W. J. New Heliconias (Heliconiaceae) from Panamá. Selbyana. Sarasota, v. 9, n.1, p.156-166, 1986.

KRESS, W. J. New Taxa and Notes on Heliconia (Heliconiaceae). Selbyana, Sarasota, v.11, p.49-53, 1989. KRESS, W.J. The taxonomy of Old World Heliconia (Heliconiaceae). Allertonia, Kauai, v.6, n.1, p.1-58, 1990. KRESS, W.J. New taxa of Heliconia. Brittonia, New York, v.43, n.4, p.253-256, 1991.

KRESS, W. J.; BETANCUR, J.; ROESEL, C.S. ; ECHEVERRYC. B.E. Lista Preliminar de las Heliconias de Colombia y Cinco Especies Nuevas. Caldasia, Bogotá, v.17, n.2, p.183-197, 1993.

KRESS, W. J. A Sinopsis of the Genus Heliconia (Heliconiaceae) in Venezuela, with one new variety. Biollania. Local, v.6, p.407-430, 1997

KRESS, W. J.; BETANCUR, J.; ECHEVERRY C. B.E. Heliconias. Lhamaradas de la selva colombiana. Bogotá, 1999, 200p.

KUNTZE, O. Revisiogenerum plantarum. Leipzig: Pars I. Artthur Felix, 1891. 20p.

MACBRIDE, , J. F. Spermatophytes mostly Peruvian. III. Publ. Field Mus. Nat. Hist. London, v.11, n.1, p. 3-35, 1931.

MACBRIDE, F. Flora of Peru. Musaceae. Field Mus. Nat. Hist., Bot. Ser., Chicago, v.13, p.717-726, 1936.

MELLO FILHO, L.E. ; SANTOS, E. Heliconiae Novae Brasiliensis IV. Bradea, Rio de Janeiro, v.11, n.16, p.95104, 1976.

MELLO FILHO, L.E. ; SANTOS, E. Heliconiae Novae Brasiliensis V. Bot. Mus. Nac., Rio de Janeiro, v.43, p.1-8, 1977.

MELLO FILHO, L.E ; SANTOS, E. Heliconiae Novae Brasiliensis VII. Bradea. Rio de Janeiro, v.41, n.3, p.370372, 1983.

MELLO FILHO, L.E. ; SANTOS, E. Heliconiae Novae Brasiliensis VIII. Bradea. Rio de Janeiro, v.44, n.4, p.350352, 1987.

MORALES, L.G. Una Heliconia nueva de Colombia. Phytologia. Huntsville, v.55, n.1, p.14-16, 1984.

NAKAI, T. Notulae ad plantas Asiae Orientalis (XVI) In: the Amomales or Zingiberales. J. Jap. Bot. v.17, n.4, p.189203, 1941.

PETERSEN, O.G. Musaceae. In: C.F.P. von Martius ; A. W. Eichler, Eds. Fl. Brasil, local, v.3, n.3, p.1-28, 1890.

PLOWMAN, T.; KRESS, W.J. ; KENNEDY, H. Heliconia zebrina: a New Name for a Handsome Peruvian Heliconia (Musaceae). Baileya, New York, v.21, n.4, p.149-157, 1982.
RODRIGUEZ, G. Revision del gênero Heliconia en Venezuela. Bol. Soc. Venezolana Ciencias Natur., Quito, v.15, n.81, p.117-130, 1954.

SANTOS, E. Revisão das espécies do gênero Heliconia L. (Musaceae s.l.) espontâneas na região fluminense. Rodriguésia, Rio de Janeiro, v.30, n.45, p.99-221, 1978.

SMITH, A. C. Studies of Pacific island plants. XVIII. New and noteworthy flowering plants from Fiji. Contris. U.S. Natl. Herb. Washington, v.37, p.69-71, 1967.

SMITH, R. R. Two new species of Heliconia (Musaceae) from de Canal Zone and Panama. Phytologia, Huntsville, v.30, p.65-70, 1975.

SMITH, R. R. Heliconia in Nicaragua. Phytologia, Huntsville, v.36, n.3, p.251-261, 1977.

SMITH, R. R. Musaceae. In: F. C. Seymour, ed. A checklist of the vascular plants of Nicaragua. Phytologia Mem. Washington, v.1, p.95-96, 1980.

SMITH, R. R. in R. McVaugh, Fl. NovoGaliciana.Washington, v.15, p.83, 1989.

STANDLEY, P. C. New Plants from Central America - VII. J. WashingtonAcad. Sci. Washington, v.17, p. 159-171, 1927. STANDLEY, P.C. Flora of Costa Rica. Musaceae. Field Mus. Nat. Hist.. Bot. Ser., Chicago, v.18, n.1, p.182-185, 1937.

STANDLEY, P.C. ; STEYERMARK, J. A. Flora of Guatemala. Musaceae. Fieldiana. Bot., Chicago, v.24, n.3, 178-186, 1952.

STILES, F. G. Ecology, flowering phenology, and hummingbird pollination of some Costa Rican Heliconia species. Ecology, AZ, v.56, p.285-301, 1975.

STILES, G. Further Data on the Genus Heliconia (Musaceae) in Northern Costa Rica. Brenesia, local v. 18, p.147-154, 1980.

STILES. G. Taxonomic and distributional notes on Costa Rican Heliconia (Musaceae), II. Parque Nacional Braulio Carillo, Cordillera Central. Brenesia, local, v.19/20, p.221-230, 1982.

TOMLINSON, P.B. An anatomical approach to the classificat of the Musaceae. J. Linn. Soc. Bot. London, v.55, n.364, p.779-809, 1959.

TOMLINSON, P.B. Phylogenyof the Scitaminae morphological and anatomical considerations. Evolution, Lawrence, v.16, p.192-213, 1962.

WATSON, D.P.; SMITH, R. R. Ornamental heliconias. Univ. Hawaii Coop. Ext. Serv. Circ. p.482. 1979.

WINKLER, H. Musaceae. IN; ENGLER, A. ; PRANTL, K. (Eds) Die Natürlinchen Pflanzenfamilien 2.ed.. 15 ${ }^{\mathrm{A}}$, p.505541, 1930..

WOODSON, R. E., Jr.; SCHERY, R. W. Flora of Panama. Musaceae. Ann. Missouri Bot. Gard. St. Louis, V.32, p.4857, 1945. 
Tabela 1. Espécies, sinonímia, ocorrência natural e variedades/cultivares de helicônias do subgênero Taeniostrobus (Kuntze) Griggs

\begin{tabular}{|c|c|c|c|c|}
\hline Espécie & $\begin{array}{l}\text { Referência da } \\
\text { descrição }\end{array}$ & Sinonímia & Ocorrência natural & Cultivares comerciais \\
\hline $\begin{array}{l}\text { H. atropurpurea } \\
\text { Daniels e Stiles }\end{array}$ & $\begin{array}{l}\text { DANIELS e } \\
\text { STILES (1979) }\end{array}$ & & Costa Rica, Panamá & Stupendous \\
\hline H. bella Kress & KRESS (1986) & & Panamá (endêmica) & \\
\hline $\begin{array}{l}\text { H. imbricata (Kuntze) } \\
\text { Baker }\end{array}$ & $\begin{array}{l}\text { Baker, 1893, } \\
\text { citado por } \\
\text { ANDERSSON } \\
(1992)\end{array}$ & $\begin{array}{l}\text { Bihaia imbricata } \\
\text { Kuntze; } \\
\text { Bihai densa Griggs } \\
\text { - H. densa (Griggs) } \\
\text { L. B. Smith }\end{array}$ & $\begin{array}{l}\text { Colômbia, Costa } \\
\text { Rica, Panamá }\end{array}$ & \\
\hline $\begin{array}{l}\text { H. reticulata (Griggs) } \\
\text { Winkl. }\end{array}$ & $\begin{array}{l}\text { Winkler, 1930, } \\
\text { citado por } \\
\text { ANDERSSON } \\
(1992)\end{array}$ & $\begin{array}{l}\text { Bihai reticulata } \\
\text { Griggs; } \\
\text { H. marmoliana } \\
\text { Dodson e Gentry }\end{array}$ & $\begin{array}{l}\text { Panamá, Costa Rica, } \\
\text { Colômbia, Equador }\end{array}$ & \\
\hline
\end{tabular}

Tabela 2. Espécies, sinonímia, ocorrência natural e variedades/cultivares de helicônias do subgênero Heliconia

\begin{tabular}{|c|c|c|c|c|}
\hline Espécie & $\begin{array}{l}\text { Referência da } \\
\text { descrição }\end{array}$ & Sinonímia & $\begin{array}{c}\text { Ocorrência } \\
\text { natural }\end{array}$ & Cultivares comerciais \\
\hline \multicolumn{5}{|c|}{ Secção Episcopales (Griggs) L. Anderss. } \\
\hline $\begin{array}{l}\text { Heliconia } \\
\text { episcopalis } \\
\text { Vell. }\end{array}$ & $\begin{array}{l}\text { Vellozo, 1825, } \\
\text { citado por } \\
\text { ANDERSSON } \\
(1992)\end{array}$ & $\begin{array}{l}\text { Bihai episcopalis (Vell.) } \\
\text { Griggs; } \\
\text { H. thyrsoidea Martius ex } \\
\text { Petersen; } \\
\text { H. ferdinando-coburgii } \\
\text { Szyszylowicz - Bihai } \\
\text { ferdinando-coburgii } \\
\text { (szyszyl.) Kuntze; } \\
\text { H. biflora Eichler ex } \\
\text { Petersen }\end{array}$ & $\begin{array}{l}\text { Colômbia, } \\
\text { Brasil, Peru, } \\
\text { Venezuela, } \\
\text { Equador, } \\
\text { Suriname, } \\
\text { Bolívia }\end{array}$ & $\begin{array}{l}\text { Spear; Red Orange Spear; Yellow } \\
\text { Spear }\end{array}$ \\
\hline \multicolumn{5}{|c|}{ Secção . Heliconia L. Anderss. } \\
\hline $\begin{array}{l}\text { Heliconia } \\
\text { aurea } \\
\text { Rodriguez }\end{array}$ & $\begin{array}{l}\text { RODRIGUEZ } \\
(1954)\end{array}$ & & $\begin{array}{l}\text { Venezuela, } \\
\text { Colômbia, } \\
\text { Guiana }\end{array}$ & Aurea Sunrise \\
\hline $\begin{array}{l}\text { Heliconia } \\
\text { bihai L. }\end{array}$ & $\begin{array}{l}\text { Lineu, } 1771 \\
\text { citado por } \\
\text { ANDERSSON } \\
(1981)\end{array}$ & $\begin{array}{l}\text { Musa bihai L. - Bihai } \\
\text { bihai (L.) Griggs; } \\
\text { H. humilis Jac.; } \\
\text { H. distans Griggs - Bihai } \\
\text { distans (Griggs) Griggs; } \\
\text { H. purpurea Griggs - } \\
\text { Bihai purpúrea (Griggs) } \\
\text { Griggs; } \\
\text { Heliconia rutila Griggs - } \\
\text { Bihai rutila (Griggs) } \\
\text { Griggs; } \\
\text { H. schaeferiana } \\
\text { Rodriguez; } \\
\text { * H. aurea Rodriguez; } \\
\text { H. jacquinii Lane ex } \\
\text { Barreiros; } \\
\text { H. caribaea auct. non } \\
\text { Lam. } \\
\text { H. bihai var. adeliana }\end{array}$ & $\begin{array}{l}\text { Jamaica, Haiti, } \\
\text { República } \\
\text { Dominicana, } \\
\text { Guadalupe, } \\
\text { Dominica, } \\
\text { Martinica, St. } \\
\text { Vincent, } \\
\text { Trinidade, } \\
\text { Colômbia, } \\
\text { Venezuela, } \\
\text { Brasil, Guiana } \\
\text { Francesa }\end{array}$ & $\begin{array}{l}\text { Arawak; Balisier; Banana Split; } \\
\text { Chocolate Dancer; Emerald Forest; } \\
\text { Five A. M.; Giant Lobster Claw; } \\
\text { Guapa; Hatchet; Halloween; Jaded } \\
\text { Forest; Kamehameha; Kuma Negro; } \\
\text { Lobster Claw One; Lobster Claw } \\
\text { Two; Nappi; Nappi Yellow; New } \\
\text { Yellow Dancer; Peachy Pink; } \\
\text { Purple Throat; Schaefer's Bihai; } \\
\text { Yellow Dancer; Dwarf Áurea; } \\
\text { Trinidad Balisier; Kaneiku; St. } \\
\text { Vincent Yellow; St. Lucia Green; } \\
\text { Schneana; Dwarf Grenada; Baby } \\
\text { Bihai; Baby Arawak; Enchanted } \\
\text { Forest; Yellow Forest; Kaneiku } \\
\text { Negro; Tobago Yellow; Pont Casse; } \\
\text { Lobster Claww Three }\end{array}$ \\
\hline
\end{tabular}


Tabela 2. continuação

\begin{tabular}{|c|c|c|c|c|}
\hline Espécie & $\begin{array}{l}\text { Referência da } \\
\text { descrição }\end{array}$ & Sinonímia & $\begin{array}{l}\text { Ocorrência } \\
\text { natural }\end{array}$ & Cultivares comerciais \\
\hline $\begin{array}{l}\text { Heliconia } \\
\text { bourgaeana Petersen }\end{array}$ & $\begin{array}{l}\text { Petersen, 1890, } \\
\text { citado por } \\
\text { ANDERSSON } \\
(1981)\end{array}$ & $\begin{array}{l}\text { Bihai bourgaeana } \\
\text { (Peters.) Kuntze; } \\
\text { * H. champneiana Griggs } \\
\text { - Bihai champneiana } \\
\text { (Griggs) Griggs; } \\
\text { H. barqueta Loes - Bihai } \\
\text { barqueta (Loes.) Griggs) }\end{array}$ & $\begin{array}{l}\text { México, } \\
\text { Guatemala, } \\
\text { Honduras }\end{array}$ & \\
\hline $\begin{array}{l}\text { Heliconia caribaea } \\
\text { Lam. }\end{array}$ & $\begin{array}{l}\text { Lamarck, 1785, } \\
\text { citado por } \\
\text { ANDERSSON } \\
(1981)\end{array}$ & $\begin{array}{l}\text { H. conferta Petersen - } \\
\text { Bihai conferta (Peters.) } \\
\text { Kuntze; } \\
\text { H. borinquena Griggs - } \\
\text { Bihai borinquena } \\
\text { (Griggs) Griggs; } \\
\text { Bihai borinquena } \\
\text { (Griggs) Griggs var. } \\
\text { coccínea Griggs e Harris; } \\
\text { H. bihai auct. non L. }\end{array}$ & $\begin{array}{l}\text { Cuba, } \\
\text { Jamaica, } \\
\text { Haiti, } \\
\text { República } \\
\text { Dominicana; } \\
\text { Antilhas, } \\
\text { Guadalupe, } \\
\text { Martinica, St. } \\
\text { Vincent }\end{array}$ & $\begin{array}{l}\text { Barbados Flat; Black } \\
\text { Magic; Chartreuse; } \\
\text { Cream; Flash; Gold; } \\
\text { Purpúrea; Kavauchi; } \\
\text { Richmond Red; Yellow } \\
\text { Sun; Green Jade; } \\
\text { Rostanom; Prince of } \\
\text { Darkness; Narcissus; St. } \\
\text { Lucia }\end{array}$ \\
\hline $\begin{array}{l}\text { H. champneiana } \\
\text { Griggs }\end{array}$ & GRIGGS (1903) & & $\begin{array}{l}\text { México, } \\
\text { Guatemala, } \\
\text { Honduras, El } \\
\text { Salvador }\end{array}$ & $\begin{array}{l}\text { Maya Blood; Maya } \\
\text { Gold; Maya Sunrise; } \\
\text { Splash; Honduras }\end{array}$ \\
\hline $\begin{array}{l}\text { Heliconia } \\
\text { lennartiana Kress }\end{array}$ & KRESS (1986) & & $\begin{array}{l}\text { Panamá } \\
\text { (endêmica) }\end{array}$ & \\
\hline $\begin{array}{l}\text { Heliconia } \\
\text { orthotricha } \\
\text { Andersson }\end{array}$ & $\begin{array}{l}\text { ANDERSSON } \\
(1981)\end{array}$ & & $\begin{array}{l}\text { Colômbia, } \\
\text { Equador, Peru }\end{array}$ & $\begin{array}{l}\text { Edge of Nite; She; } \\
\text { Butterfield; Eden Pink; } \\
\text { Hot Pink; Imperial; } \\
\text { Jungle Girl; Lehua; } \\
\text { Lemon; Macas Pink; } \\
\text { Orange Crush; Palest } \\
\text { Pink; Ruby Red; } \\
\text { Tricolor; Velvet; Yellow } \\
\text { Base }\end{array}$ \\
\hline $\begin{array}{l}\text { Heliconia } \\
\text { rodriguensis Arist. }\end{array}$ & $\begin{array}{l}\text { ARISTEGUIETA } \\
\text { (1961) }\end{array}$ & & $\begin{array}{l}\text { Venezuela } \\
\text { (endêmica) }\end{array}$ & \\
\hline $\begin{array}{l}\text { Heliconia stricta } \\
\text { Huber }\end{array}$ & HUBER (1906) & $\begin{array}{l}\text { Bihai stricta (Huber) } \\
\text { Griggs; } \\
\text { H. humilis auct. non Jacq. } \\
\text { H. tricolor Abalo e } \\
\text { Morales }\end{array}$ & $\begin{array}{l}\text { Colômbia, } \\
\text { Venezuela, } \\
\text { Suriname, } \\
\text { Equador, } \\
\text { Peru, Bolívia, } \\
\text { Brasil }\end{array}$ & $\begin{array}{l}\text { Bob Wilson; Bucky; } \\
\text { Burning Desire; Canary } \\
\text { Yellow; Carli's } \\
\text { Sharonii, Castanza; } \\
\text { Cochabamba; Cooper's } \\
\text { Sharonii; Dark Desire; } \\
\text { Dimples; Dorado Gold; } \\
\text { Dwarf Jamaican; Dwarf } \\
\text { Wag; Elsie; Fire Bird; } \\
\text { Iris; Las Cruces; Lee } \\
\text { Moore; Royal; Olivera's } \\
\text { Sharonii; Orange; Oriole } \\
\text { Orange; Pascuita; Petite; } \\
\text { Royal Tagami; Slash } \\
\text { and Burn; Swish; } \\
\text { Tagami; Jamaica }\end{array}$ \\
\hline $\begin{array}{l}\text { Heliconia } \\
\text { wagneriana Petersen }\end{array}$ & $\begin{array}{l}\text { Petersen, 1890, } \\
\text { citado por } \\
\text { ANDERSSON } \\
(1981)\end{array}$ & $\begin{array}{l}\text { Bihai wagneriana } \\
\text { (Peters.) Kuntze; } \\
\text { H. elongata Griggs - } \\
\text { Bihai elongata (Griggs) } \\
\text { Griggs } \\
\text { * H. lennartiana Kress }\end{array}$ & $\begin{array}{l}\text { Guatemala, } \\
\text { Belize, } \\
\text { Honduras, } \\
\text { Costa Rica, } \\
\text { Panamá, } \\
\text { Nicaragua, } \\
\text { Colômbia }\end{array}$ & Turbo \\
\hline
\end{tabular}


Tabela 2. continuação

\begin{tabular}{|c|c|c|c|c|}
\hline Espécie & $\begin{array}{l}\text { Referência da } \\
\text { descrição }\end{array}$ & Ocorrênci & Cultivares & omerciais \\
\hline \multicolumn{5}{|c|}{ Secção Tortex L. Anderss. } \\
\hline $\begin{array}{l}\text { H. albicosta } \\
\text { (Daniels \& } \\
\text { Stiles) L. } \\
\text { Andersson }\end{array}$ & ANDERSSON (1992) & $\begin{array}{l}\text { H. irrasa (ssp. undulata) var. } \\
\text { albicosta Daniels \& Stiles }\end{array}$ & Costa Rica (endêmica) & \\
\hline $\begin{array}{l}\text { Heliconia } \\
\text { antioquiensis } \\
\text { Abalo \& Morales }\end{array}$ & $\begin{array}{l}\text { ABALO \& MORALES } \\
\text { (1985) } \\
\text { s ANDERSSON (1992) } \\
\text { sugere ser um híbrido } \\
\text { entre H. latispatha e H. } \\
\text { spathocircinata }\end{array}$ & & Colômbia (endêmica) & \\
\hline $\begin{array}{l}\text { Heliconia } \\
\text { beckneri R. R. } \\
\text { Smith }\end{array}$ & SMITH (1975) & & Costa Rica, Panamá & $\begin{array}{l}\text { Hall Red; } \\
\text { Yellow Gyre }\end{array}$ \\
\hline $\begin{array}{l}\text { Heliconia } \\
\text { cucullata Kress } \\
\text { \& Andersson }\end{array}$ & KRESS (1989) & & Panamá (endêmica) & \\
\hline $\begin{array}{l}\text { Heliconia } \\
\text { faunorum Kress } \\
\text { \& Andersson }\end{array}$ & KRESS (1989) & & Panamá (endêmica) & \\
\hline $\begin{array}{l}\text { Heliconia irrasa } \\
\text { R.R. Smith }\end{array}$ & SMITH (1975) & $\begin{array}{l}\text { H. irrasa (ssp. irrasa) var. } \\
\text { glabra Daniels \& Stiles }\end{array}$ & Costa Rica, Panamá, & \\
\hline $\begin{array}{l}\text { Heliconia } \\
\text { latispatha Benth. }\end{array}$ & $\begin{array}{l}\text { Bentham, 1844, citado } \\
\text { por ANDERSSON } \\
(1992)\end{array}$ & $\begin{array}{l}\text { Bihai latispatha Benth.; } \\
\text { H. aequatoriensis Loes. }\end{array}$ & $\begin{array}{l}\text { Jamaica, México, Brasil, } \\
\text { Belize, Panamá, } \\
\text { Guatemala, El Salvador, } \\
\text { Costa Rica, Nicarágua, } \\
\text { Honduras, Equador, } \\
\text { Colômbia, Venezuela }\end{array}$ & $\begin{array}{l}\text { Distans, Red; } \\
\text { Yellow Gyro; } \\
\text { Orange Gyro; } \\
\text { Burnt Gold; } \\
\text { Fat Lat; } \\
\text { Mexican Gold }\end{array}$ \\
\hline $\begin{array}{l}\text { Heliconia } \\
\text { lindsayana Kress }\end{array}$ & KRESS (1986) & & Panamá (endêmica) & \\
\hline $\begin{array}{l}\text { Heliconia lutea } \\
\text { Kress }\end{array}$ & KRESS (1986) & & Panamá (endêmica) & \\
\hline $\begin{array}{l}\text { Heliconia } \\
\text { monteverdensis } \\
\text { Daniels \& Stiles }\end{array}$ & $\begin{array}{l}\text { DANIELS \& STILES } \\
\text { (1979) }\end{array}$ & $\begin{array}{l}\text { H. vulcanicola Stiles - } \\
\text { Heliconia monteverdensis } \\
\text { Daniels \& Stiles var. } \\
\text { vulcanicola (Stiles) }\end{array}$ & Costa Rica (endêmica) & \\
\hline $\begin{array}{l}\text { Heliconia } \\
\text { monteverdensis } \\
\text { Daniels \& Stiles } \\
\text { var. vulcanicola } \\
\text { (Stiles) Kress }\end{array}$ & KRESS (1989) & H. vulcanicola Stiles & Costa Rica & \\
\hline $\begin{array}{l}\text { H. nubigena L. } \\
\text { Andersson }\end{array}$ & ANDERSSON (1992) & & Costa Rica, Panamá & \\
\hline $\begin{array}{l}\text { Heliconia } \\
\text { sarapiquensis } \\
\text { Daniels \& Stiles }\end{array}$ & $\begin{array}{l}\text { DANIELS \& STILES } \\
(1979)\end{array}$ & * H. lindsayana Kress & Panamá, Costa Rica & \\
\hline $\begin{array}{l}\text { Heliconia } \\
\text { spathocircinata } \\
\text { Aristeg. }\end{array}$ & ARISTEGUIETA (1961) & $\begin{array}{l}\text { H. spatho-circinada } \\
\text { Aristeguieta; } \\
\text { H. linneana Lane ex Barreiros; } \\
\text { H. linneana var. flava } \\
\text { Barreiros; } \\
\text { H. paraensis Huber ex Santos; } \\
\text { H. rollinsii Lane ex Santos }\end{array}$ & $\begin{array}{l}\text { Tobago, Trinidade, } \\
\text { Panamá, Colômbia, } \\
\text { Venezuela, Guiana, } \\
\text { Suriname, Brasil, Equador, } \\
\text { Peru, Bolivia }\end{array}$ & \\
\hline
\end{tabular}


Tabela 2. continuação

\begin{tabular}{|c|c|c|c|c|}
\hline Espécie & $\begin{array}{l}\text { Referência da } \\
\text { descrição }\end{array}$ & Sinonímia & Ocorrência natural & $\begin{array}{l}\text { Cultivares } \\
\text { comerciais }\end{array}$ \\
\hline $\begin{array}{l}\text { Heliconia } \\
\text { thomasiana Kress }\end{array}$ & $\begin{array}{l}\text { KRESS } \\
(1986)\end{array}$ & & Panamá (endêmica) & \\
\hline $\begin{array}{l}\text { Heliconia tortuosa } \\
\text { Griggs }\end{array}$ & $\begin{array}{l}\text { GRIGGS } \\
(1903)\end{array}$ & Bihai tortuosa (Griggs) Griggs & $\begin{array}{l}\text { México, Belize, } \\
\text { Guatemala, } \\
\text { Honduras, } \\
\text { Nicarágua, Costa } \\
\text { Rica, Panamá }\end{array}$ & $\begin{array}{l}\text { Red Twist; } \\
\text { Yellow Twist }\end{array}$ \\
\hline $\begin{array}{l}\text { Heliconia } \\
\text { umbrophila } \\
\text { Daniels \& Stiles }\end{array}$ & $\begin{array}{l}\text { DANIELS \& } \\
\text { STILES } \\
(1979)\end{array}$ & & $\begin{array}{l}\text { Costa Rica } \\
\text { (endêmica) }\end{array}$ & \\
\hline $\begin{array}{l}\text { Heliconia undulata } \\
\text { (Daniels \& Stiles) } \\
\text { L. Andersson }\end{array}$ & $\begin{array}{l}\text { ANDERSSO } \\
\mathrm{N}(1992)\end{array}$ & $\begin{array}{l}\text { H. irrasa (ssp. undulata) var. } \\
\text { undulata Daniels \& Stiles }\end{array}$ & $\begin{array}{l}\text { Costa Rica } \\
\text { (endêmica) }\end{array}$ & \\
\hline
\end{tabular}

Secção Tenebria L. Anderss.

\begin{tabular}{|c|c|c|c|}
\hline $\begin{array}{l}\text { Heliconia } \\
\text { lourteigiae } \\
\text { Emygdio \& Santos }\end{array}$ & $\begin{array}{l}\text { MELLO } \\
\text { FILHO \& } \\
\text { SANTOS } \\
(1977)\end{array}$ & H. lourtegii Emygdio \& Santos & $\begin{array}{l}\text { Venezuela, Peru, } \\
\text { Colômbia, Brasil, } \\
\text { Suriname, Guiana } \\
\text { Francesa }\end{array}$ \\
\hline $\begin{array}{l}\text { Heliconia } \\
\text { tenebrosa Macbrid. }\end{array}$ & $\begin{array}{l}\text { MACBRIDE } \\
\text { (1931) }\end{array}$ & & Brasil, Peru \\
\hline
\end{tabular}

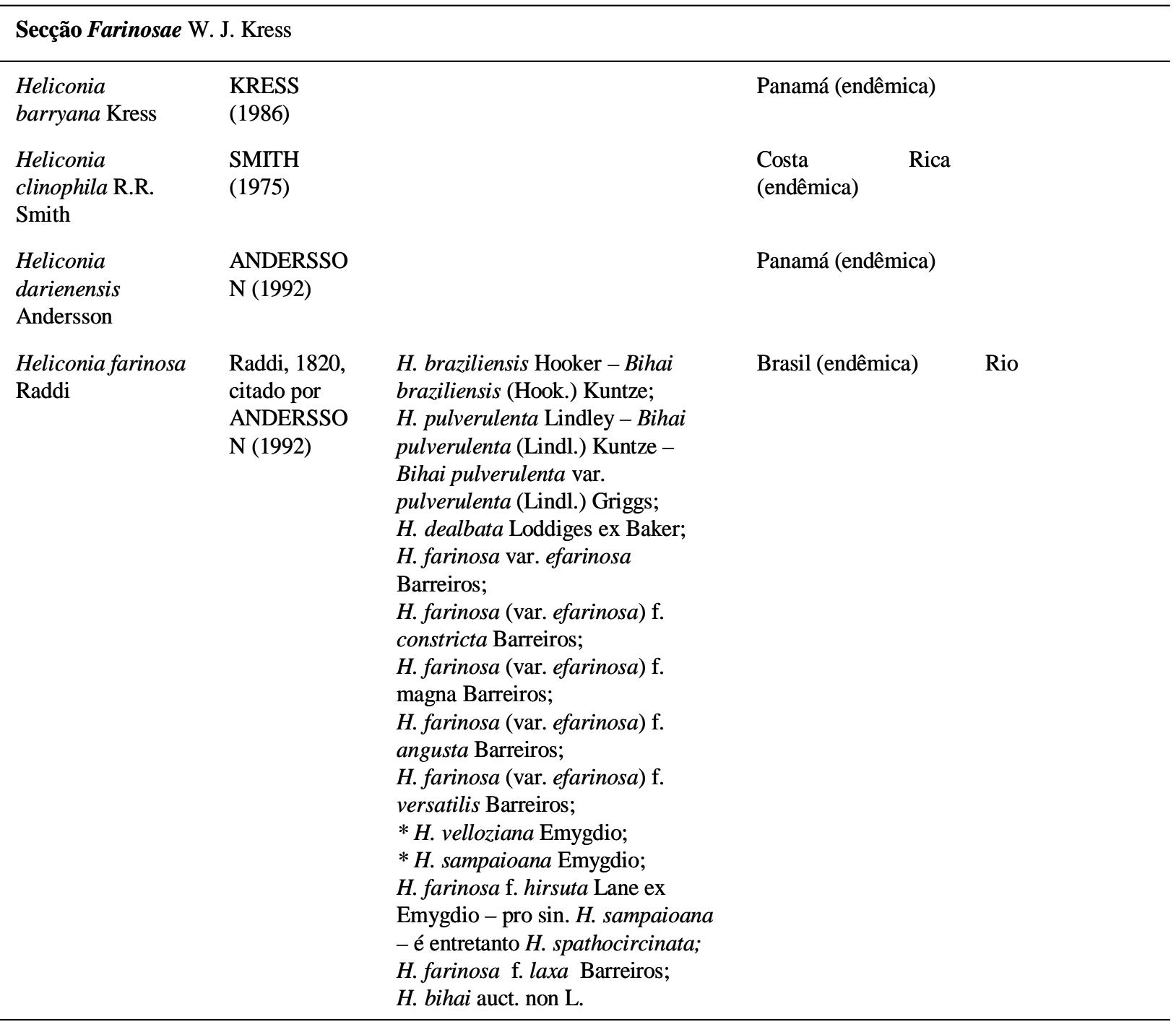


Tabela 2. conclusão

\begin{tabular}{|c|c|c|c|c|}
\hline Espécie & $\begin{array}{l}\text { Referência da } \\
\text { descrição }\end{array}$ & Sinonímia & Ocorrência natural & Cultivares comerciais \\
\hline $\begin{array}{l}\text { Heliconia ignescens } \\
\text { Daniels \& Stiles }\end{array}$ & $\begin{array}{l}\text { DANIELS \& STILES } \\
(1979)\end{array}$ & $\begin{array}{l}\text { H. gracilis } \\
\text { Daniels \& } \\
\text { Stiles }\end{array}$ & Costa Rica, Panamá & Gil Daniels, John Hall \\
\hline $\begin{array}{l}\text { Heliconia kautzhiana } \\
\text { Emygdio \& Santos }\end{array}$ & $\begin{array}{l}\text { MELLO FILHO \& } \\
\text { SANTOS (1987) }\end{array}$ & & Brasil (endêmica) & \\
\hline $\begin{array}{l}\text { Heliconia lankesteri } \\
\text { Standley }\end{array}$ & $\begin{array}{l}\text { Standley, 1927, citado } \\
\text { por ANDERSSON } \\
(1992)\end{array}$ & $\begin{array}{l}\text { H. lankesteri } \\
\text { var. rubra } \\
\text { Daniels \& } \\
\text { Stiles }\end{array}$ & Costa Rica, Panamá & \\
\hline $\begin{array}{l}\text { Heliconia librata } \\
\text { Griggs }\end{array}$ & GRIGGS (1903) & & $\begin{array}{l}\text { México, Belize, } \\
\text { Guatemala, Honduras, } \\
\text { Nicarágua }\end{array}$ & \\
\hline $\begin{array}{l}\text { Heliconia rivularis } \\
\text { Emygdio \& Santos }\end{array}$ & $\begin{array}{l}\text { MELLO FILHO \& } \\
\text { SANTOS (1977) }\end{array}$ & & Brasil (endêmica) & Brazilian Firefly \\
\hline $\begin{array}{l}\text { Heliconia rodriguezii } \\
\text { Stiles }\end{array}$ & STILES (1982) & & Costa Rica (endêmica) & \\
\hline $\begin{array}{l}\text { Heliconia sampaioana } \\
\text { Melo Filho }\end{array}$ & $\begin{array}{l}\text { MELLO FILHO \& } \\
\text { SANTOS (1976) }\end{array}$ & & Brasil (endêmica) & \\
\hline $\begin{array}{l}\text { Heliconia velloziana } \\
\text { Emygdio }\end{array}$ & $\begin{array}{l}\text { MELLO FILHO } \\
(1975)\end{array}$ & & Brasil (endêmica) & \\
\hline \multicolumn{5}{|c|}{ Secção Complanatae W. J. Kress } \\
\hline $\begin{array}{l}\text { H. atratensis Abalo \& } \\
\text { Morales }\end{array}$ & $\begin{array}{l}\text { ABALO \& } \\
\text { MORALES (1982) }\end{array}$ & & Colômbia (endêmica) & \\
\hline $\begin{array}{l}\text { Heliconia brenneri } \\
\text { Abalo \& Morales }\end{array}$ & $\begin{array}{l}\text { ABALO \& } \\
\text { MORALES (1983a) }\end{array}$ & & Equador (endêmica) & \\
\hline $\begin{array}{l}\text { Heliconia foreroi } \\
\text { Abalo \& Morales }\end{array}$ & $\begin{array}{l}\text { ABALO \& } \\
\text { MORALES (1991) }\end{array}$ & & Colômbia (endêmica) & \\
\hline
\end{tabular}

* espécies onde exitem divergências entre taxonomistas

Tabela 3. Espécies, sinonímia, ocorrência natural e variedades/cultivares de helicônias do subgênero Stenochlamys Baker

\begin{tabular}{|c|c|c|c|c|}
\hline Espécie & $\begin{array}{l}\text { Referência da } \\
\text { descrição }\end{array}$ & S inonímia & Ocorrência natural & Cultivares comerciais \\
\hline \multicolumn{5}{|c|}{ Secção Lanea L. Anderss. } \\
\hline $\begin{array}{l}\text { Heliconia. adflexa } \\
\text { (Griggs) Standl. }\end{array}$ & $\begin{array}{l}\text { STANDLEY } \\
(1927)\end{array}$ & Bihai adflexa Griggs. & $\begin{array}{l}\text { Honduras, } \\
\text { Guatemala, } \\
\text { México }\end{array}$ & \\
\hline $\begin{array}{l}\text { Heliconia aemygdiana } \\
\text { B. Marx;Heliconia } \\
\text { aemygdiana B. Marx } \\
\text { subsp. } \\
\text { aemygdiana;Heliconia } \\
\text { aemygdiana B. Marx } \\
\text { subsp. transandina }\end{array}$ & $\begin{array}{l}\text { BURLE MARX } \\
\text { (1974);ANDERS } \\
\text { SON (1985b) }\end{array}$ & $\begin{array}{l}\text { H. dasyantha Kock } \\
\text { \& Buché var. rosea } \\
\text { Loes.;H.aemygdiana } \\
\text { B. Marx;H. } \\
\text { zygolopha Lane ex } \\
\text { Santos;H. emygdiana } \\
\text { B. Marx }\end{array}$ & $\begin{array}{l}\text { Colômbia, Brasil, } \\
\text { Peru, Equador, } \\
\text { Bolívia, } \\
\text { Venezuela }\end{array}$ & $\begin{array}{l}\text { Enchanted Forest; Purple } \\
\text { Peru }\end{array}$ \\
\hline $\begin{array}{l}\text { Heliconia burleana } \\
\text { Abalo \& Morales }\end{array}$ & $\begin{array}{l}\text { ABALO \& } \\
\text { MORALES } \\
(1983 a)\end{array}$ & & $\begin{array}{l}\text { Colômbia, } \\
\text { Equador }\end{array}$ & \\
\hline $\begin{array}{l}\text { Heliconia fugax } \\
\text { Andersson }\end{array}$ & $\begin{array}{l}\text { ANDERSSON } \\
\text { (1985a) }\end{array}$ & & Peru (endêmica) & \\
\hline
\end{tabular}


Tabela 3. continuação

\begin{tabular}{|c|c|c|c|c|}
\hline Espécie & $\begin{array}{l}\text { Referência da } \\
\text { descrição }\end{array}$ & S inonímia & $\begin{array}{l}\text { Ocorrência } \\
\text { natural }\end{array}$ & $\begin{array}{l}\text { Cultivares } \\
\text { comerciais }\end{array}$ \\
\hline $\begin{array}{l}\text { Heliconia gaiboriana } \\
\text { Abalo \& Morales }\end{array}$ & $\begin{array}{l}\text { ABALO \& } \\
\text { MORALES } \\
(1991)\end{array}$ & & $\begin{array}{l}\text { Equador } \\
\text { (endêmica) }\end{array}$ & \\
\hline $\begin{array}{l}\text { Heliconia gilbertiana } \\
\text { Abalo \& Morales }\end{array}$ & $\begin{array}{l}\text { ABALO \& } \\
\text { MORALES } \\
(1983 b)\end{array}$ & $\begin{array}{l}\text { H. aristeguietae Abalo \& Morales; } \\
\text { Heliconia scarlatina Abalo \& } \\
\text { Morales }\end{array}$ & $\begin{array}{l}\text { Colômbia, } \\
\text { Panamá, } \\
\text { Peru }\end{array}$ & \\
\hline $\begin{array}{l}\text { Heliconia gloriosa Abalo } \\
\text { \& Morales }\end{array}$ & $\begin{array}{l}\text { ABALO \& } \\
\text { MORALES } \\
(1991)\end{array}$ & & $\begin{array}{l}\text { Peru } \\
\text { (endêmica) }\end{array}$ & \\
\hline $\begin{array}{l}\text { Heliconia impudica } \\
\text { Abalo \& Morales }\end{array}$ & $\begin{array}{l}\text { ABALO \& } \\
\text { MORALES } \\
\text { (1983a) }\end{array}$ & H. consueloi Abalo \& Morales & $\begin{array}{l}\text { Equador } \\
\text { (endêmica) }\end{array}$ & \\
\hline $\begin{array}{l}\text { Heliconia lingulata Ruiz } \\
\text { \& Pav. }\end{array}$ & $\begin{array}{l}\text { Ruiz \& Pavón, } \\
1802 \text { citados } \\
\text { por } \\
\text { ANDERSSON } \\
(1985 b)\end{array}$ & $\begin{array}{l}\text { Bihai lingulata (R. \& P.) Griggs; } H \text {. } \\
\text { weberbaueri Loes. }\end{array}$ & $\begin{array}{l}\text { Peru, } \\
\text { Bolívia }\end{array}$ & $\begin{array}{l}\text { Fan; Red } \\
\text { Tip Fan; } \\
\text { Pagoda; } \\
\text { Birdeyan } \\
\text { a; Spiral } \\
\text { Fan }\end{array}$ \\
\hline $\begin{array}{l}\text { Heliconia lophocarpa } \\
\text { Daniels \& Stiles }\end{array}$ & $\begin{array}{l}\text { DANIELS \& } \\
\text { STILES (1979) }\end{array}$ & & $\begin{array}{l}\text { Costa Rica, } \\
\text { Panamá }\end{array}$ & \\
\hline $\begin{array}{l}\text { Heliconia meridensis } \\
\text { Klotzsch }\end{array}$ & $\begin{array}{l}\text { Klotzsch, } \\
\text { 1847, citado } \\
\text { por } \\
\text { ANDERSSON } \\
(1985 a)\end{array}$ & $\begin{array}{l}\text { Bihai meridensis (Kl.) Kuntze; } H \text {. } \\
\text { schneeana Steyermark; } H \text {. falcata } \\
\text { Barreiros; H. colombiana Abalo \& } \\
\text { Morales; H. mincana Abalo \& } \\
\text { Morales }\end{array}$ & $\begin{array}{l}\text { Colômbia, } \\
\text { Venezuela }\end{array}$ & \\
\hline $\begin{array}{l}\text { Heliconia mincana Abalo } \\
\text { \& Morales }\end{array}$ & $\begin{array}{l}\text { ABALO \& } \\
\text { MORALES } \\
(1983 b)\end{array}$ & & $\begin{array}{l}\text { Colômbia } \\
\text { (endêmica) }\end{array}$ & \\
\hline $\begin{array}{l}\text { H. pseudoaemygdiana } \\
\text { Emygdio \& Santos }\end{array}$ & $\begin{array}{l}\text { MELLO } \\
\text { FILHO \& } \\
\text { SANTOS } \\
(1983)\end{array}$ & $\begin{array}{l}\text { Heliconia pseudoaemygdiana } \\
\text { Emygdio \& Santos }\end{array}$ & $\begin{array}{l}\text { Brasil, } \\
\text { Peru, } \\
\text { Bolívia }\end{array}$ & Birdiana \\
\hline $\begin{array}{l}\text { Heliconia schiedeana } \mathrm{Kl} . \\
\text { Heliconia schiedeana } \mathrm{Kl} . \\
\text { var. schiedeana }\end{array}$ & $\begin{array}{l}\text { Klotzsch, } \\
\text { 1847, citado } \\
\text { por } \\
\text { ANDERSSON } \\
\text { (1985a) } \\
\text { SMITH (1977) }\end{array}$ & $\begin{array}{l}\text { Bihai schiedeana (Kl.) Kuntze; } \\
\text { Bihai geniculata Griggs - H. } \\
\text { geniculata (Griggs) L. B. Smith; } H \text {. } \\
\text { potchultensis Conzatti }\end{array}$ & $\begin{array}{l}\text { México } \\
\text { (endêmica) } \\
\text { México } \\
\text { (endêmica) }\end{array}$ & \\
\hline Heliconia spissa Griggs & $\begin{array}{l}\text { GRIGGS } \\
(1903)\end{array}$ & $\begin{array}{l}\text { Bihai spissa (Griggs) Griggs; H. } \\
\text { schiedeana Kl. var. spissa (Griggs) } \\
\text { R. R. Smith }\end{array}$ & & \\
\hline $\begin{array}{l}\text { Heliconia virginallis } \\
\text { Abalo \& Morales }\end{array}$ & $\begin{array}{l}\text { ABALO \& } \\
\text { MORALES } \\
(1983 a)\end{array}$ & & $\begin{array}{l}\text { Equador } \\
\text { (endêmica) }\end{array}$ & \\
\hline $\begin{array}{l}\text { Heliconia willisiana } \\
\text { Abalo \& Morales }\end{array}$ & $\begin{array}{l}\text { ABALO \& } \\
\text { MORALES } \\
(1983 a)\end{array}$ & & $\begin{array}{l}\text { Equador } \\
\text { (endêmica) }\end{array}$ & \\
\hline $\begin{array}{l}\text { Heliconia zebrina Plow., } \\
\text { Kress \& Kennedy }\end{array}$ & $\begin{array}{l}\text { PLOWMAN, } \\
\text { KRESS \& } \\
\text { KENNEDY } \\
(1982)\end{array}$ & Heliconia variegata Loes, non Jacq. & $\begin{array}{l}\text { Peru } \\
\text { (endêmica) }\end{array}$ & $\begin{array}{l}\text { Inca, } \\
\text { Tim } \\
\text { Plowman }\end{array}$ \\
\hline
\end{tabular}


Tabela 3. continuação

\begin{tabular}{|c|c|c|c|c|}
\hline Espécie & $\begin{array}{l}\text { Referência da } \\
\text { descrição }\end{array}$ & S inonímia & $\begin{array}{l}\text { Ocorrência } \\
\text { natural }\end{array}$ & $\begin{array}{l}\text { Cultivares } \\
\text { comerciais }\end{array}$ \\
\hline
\end{tabular}

Seç̧ão Stenochlamys (Baker) Schum.

\begin{tabular}{|c|c|c|c|c|}
\hline $\begin{array}{l}\text { Heliconia } \\
\text { acuminata L. C. } \\
\text { Rich; Heliconia } \\
\text { acuminata L. C. } \\
\text { Rich subsp } \\
\text { acuminata;Helic } \\
\text { onia acuminata } \\
\text { L. C. Rich } \\
\text { subsp. } \\
\text { immaculata } \\
\text { Anders.;Helicon } \\
\text { ia acuminata } \\
\text { L.C. Rich subsp. } \\
\text { occidentalis } \\
\text { Anders.;Helicon } \\
\text { ia acuminata L. } \\
\text { C. Rich subsp. } \\
\text { psittacorastra } \\
\text { Anders. }\end{array}$ & $\begin{array}{l}\text { Richard, 1831, citado } \\
\text { por ANDERSSON } \\
\text { (1985a) ANDERSSON } \\
\text { (1985a) }\end{array}$ & $\begin{array}{l}\text { H. acuminata L.C.Rich; Bihai } \\
\text { acuminata (L.C.Rich) Kuntze; } H \text {. } \\
\text { psittacorum L.f. var. flexuosa } \\
\text { Petersen; H. roseoflava Loes.;H. } \\
\text { tarumaensis Barreiros; } H . \\
\text { psittacorum auct. non L.f., } \\
\text { Macbride }\end{array}$ & $\begin{array}{l}\text { Guiana } \\
\text { Francesa, } \\
\text { Guiana, } \\
\text { Suriname, } \\
\text { Peru } \\
\text { (endêmica), } \\
\text { Brasil, } \\
\text { Colômbia, } \\
\text { Venezuela, } \\
\text { Bolívia, } \\
\text { Equador }\end{array}$ & $\begin{array}{l}\text { Cheri R., Ruby, } \\
\text { Tarumã e Yellow } \\
\text { Waltz }\end{array}$ \\
\hline $\begin{array}{l}\text { Heliconia } \\
\text { angusta Vell. }\end{array}$ & $\begin{array}{l}\text { Vellozo, 1825, citado } \\
\text { por ANDERSSON } \\
\text { (1985a) }\end{array}$ & $\begin{array}{l}\text { Bihai angusta (Vell.) Griggs; } H \text {. } \\
\text { bicolor Bentham; H. angustifolia } \\
\text { Hooker - Bihai angustifolia } \\
\text { (Hook.) Kuntze; H. bidendata } \\
\text { Barreiros; H. simulans Lane ex } \\
\text { Barreiros; H. laneana Barreiros; } \\
\text { H. laneana Barr. f. flava } \\
\text { Barreiros - H. laneana Barr. var. } \\
\text { flava (Barr.) Santos; H. laneana } \\
\text { Barr. f. elatior Barreiros; H. } \\
\text { aurorea Emygdio \& Santos; } H \text {. } \\
\text { citrina Emygdio \& Santos; } H \text {. } \\
\text { fluminensis Emygdio \& Santos; } \\
\text { H. lacletteana Emygdio \& } \\
\text { Santos; H. brasiliensis auct. non } \\
\text { Hook. }\end{array}$ & $\begin{array}{l}\text { Brasil } \\
\text { (endêmica) }\end{array}$ & $\begin{array}{l}\text { Flava; Holiday; } \\
\text { Large Christmans; } \\
\text { March Christmans; } \\
\text { Orange Christmans; } \\
\text { Yellow Christmans }\end{array}$ \\
\hline $\begin{array}{l}\text { Heliconia } \\
\text { brachyantha } \\
\text { Andersson }\end{array}$ & ANDERSSON (1985a) & & $\begin{array}{l}\text { Panamá, } \\
\text { Colômbia, } \\
\text { Venezuela }\end{array}$ & \\
\hline $\begin{array}{l}\text { Heliconia } \\
\text { psittacorum L. }\end{array}$ & $\begin{array}{l}\text { Lineu, 1781, citado por } \\
\text { ANDERSSON (1985a) }\end{array}$ & $\begin{array}{l}\text { Bihai psittacorum (L. f.) Kuntze; } \\
\text { H. humilis (Aubl.) Jacq. - Musa } \\
\text { humilis Aublet; H. ballia L. C. } \\
\text { Richard.; H. marantifolia Shaw; } \\
\text { H. swartziana Roemer \& } \\
\text { Schultes; H. cannoidea L.C. Rich } \\
\text { - H. hirsuta L. f. var. cannoidea } \\
\text { (L.C.Rich.) Baker - Bihai } \\
\text { cannoidea (L.C.Richard) Kuntze; } \\
\text { H. schomburgkiana Kl. - H. } \\
\text { psittacorum L. f. var. } \\
\text { schomburgkiana (Kl.) Baker; H. } \\
\text { andrewsii Kl.; H. psittacorum L. } \\
\text { f. var. B spathacea Eichler ex } \\
\text { Petersen; H. psittacorum L. f. } \\
\text { var.y robusta Eichler ex } \\
\text { Petersen; H. refracta Martens ex } \\
\text { Baker; Bihai silvestris Gleason - } \\
\text { H. silvestris (Gleason) L. B. } \\
\text { Smith; H. psittacorum L. f. } \\
\text { rhizomatosa Aristeguieta; H. } \\
\text { goiasensis Barreiros;H. bahiensis } \\
\text { Barreiros }\end{array}$ & $\begin{array}{l}\text { Montserrat, } \\
\text { Guadalupe, } \\
\text { Martinica, } \\
\text { St. Vincent, } \\
\text { Trinidade, } \\
\text { Tobago, } \\
\text { Colômbia, } \\
\text { Venezuela, } \\
\text { Guiana, } \\
\text { Suriname, } \\
\text { Guiana } \\
\text { Francesa, } \\
\text { Brasil, } \\
\text { Bolívia }\end{array}$ & $\begin{array}{l}\text { Andrômeda; Black } \\
\text { Cherry, Borinquen } \\
\text { Midnight; } \\
\text { Choconiana; } \\
\text { Flamingo; Fuchsia; } \\
\text { Kathy; Lady Di; } \\
\text { Lena; Lílian; Lizette; } \\
\text { Parakeet; Peter } \\
\text { Bacon; Petra; Pink; } \\
\text { Ruby; St. Vincent } \\
\text { Red; Sassy; } \\
\text { Shamrock; } \\
\text { Strawberries and } \\
\text { Cream; Suriname } \\
\text { Sassy; Kaliedoscope; } \\
\text { Adrian's Red; Dwarf } \\
\text { Pink; Rubra; } \\
\text { Silvestris; Coverdia } \\
\text { Red; Doublé B Gold; } \\
\text { Kanasayana; Karen; } \\
\text { Marion; Sybel; Tay }\end{array}$ \\
\hline
\end{tabular}


Tabela 3. continuação

\begin{tabular}{|c|c|c|c|c|}
\hline Espécie & Referência da descrição & Sinonímia & $\begin{array}{c}\text { Ocorrência } \\
\text { natural }\end{array}$ & Cultivares comerciais \\
\hline Heliconia richardiana Miq. & $\begin{array}{l}\text { Miquel, 1844, citado por } \\
\text { ANDERSSON (1985a) }\end{array}$ & $\begin{array}{l}\text { H. glauca Poiteau ex } \\
\text { Verlot - Bihai } \\
\text { glauca (Poit.) } \\
\text { Kuntze }\end{array}$ & $\begin{array}{l}\text { Venezuela, } \\
\text { Guiana, } \\
\text { Suriname, } \\
\text { Guiana } \\
\text { Francesa, } \\
\text { Brasil }\end{array}$ & Little Richard \\
\hline Heliconia timothei Andersson & ANDERSSON (1985a) & & Peru,, Brasil & \\
\hline
\end{tabular}

Seç̧ão Proximochlamys Anderss.

Heliconia densiflora Verlot;

Heliconia densiflora Verlot ssp.

Densiflora; Heliconia densiflora

Verlot subsp. angustifolia Andersson

$\begin{array}{llll}\text { Verlot, 1869, citado por } & \text { H. densiflora Verlot } & \text { Guiana, } & \text { Fire Flash } \\ \text { ANDERSSON (1985a) } & \text { - Bihai densiflora } & \text { Colômbia, } \\ \text { ANDERSSON (1985a) } & \text { (Verlot) Kuntze } & \text { Trinidad, } \\ & & \text { Venezuela, } \\ & & \text { Suriname, } \\ & \text { Guiana } \\ & \text { Francesa, } \\ & & \text { Brasil, Bolívia }\end{array}$

Secção Lasia L. Anderss.

\begin{tabular}{|c|c|c|c|}
\hline Heliconia dasyantha Koch \& Bouché & $\begin{array}{l}\text { Koch \& Bouché, 1854, } \\
\text { citado por } \\
\text { ANDERSSON (1985a) }\end{array}$ & & $\begin{array}{l}\text { Suriname e } \\
\text { Guiana } \\
\text { Francesa }\end{array}$ \\
\hline Heliconia estherae Abalo \& Morales & $\begin{array}{l}\text { ABALO \& MORALES } \\
\text { (1982) }\end{array}$ & & $\begin{array}{l}\text { Colômbia } \\
\text { (endêmica) }\end{array}$ \\
\hline Heliconia julianii Souza Barreiros & BARREIROS (1976) & & $\begin{array}{l}\text { Colômbia, } \\
\text { Equador } \\
\text { Venezuela, } \\
\text { Brasil, Peru }\end{array}$ \\
\hline Heliconia lasiorachis Andersson & ANDERSSON (1985b) & $\begin{array}{l}\text { H. brasiliensis auct. } \\
\text { non Hooker }\end{array}$ & $\begin{array}{l}\text { Peru, } \\
\text { Colômbia, } \\
\text { Brasil, } \\
\text { Equador }\end{array}$ \\
\hline Heliconia velutina Andersson & ANDERSSON (1985b) & $\begin{array}{l}\text { H. brasiliensis auct. } \\
\text { non Hook. }\end{array}$ & $\begin{array}{l}\text { Colômbia, } \\
\text { Brasil, } \\
\text { Equador, Peru }\end{array}$ \\
\hline
\end{tabular}

Secção Cannastrum L. Anderss.

Heliconia berryi Abalo \& Morales
Heliconia calatheaphylla Daniels \&
Stiles
Heliconia metallica Planch. \& Linden
ex Hook..
ex Hook.

Heliconia osaensis Cuf.; Heliconia osaensis Cuf. var. rubescens Stiles

\section{ABALO \& MORALES \\ (1991)}

DANIELS \& STILES

(1979)

Hooker, 1862, citado por ANDERSSON (1985b)

Citada por

ANDERSSON (1985b)

STILES (1980)
Equador

(endêmica)

Costa Rica

(endêmica)

Bihai metallica Honduras,

(Hook.) Kuntze; $H$. Nicaragua, vinosa Bull. Ex Costa Rica,

Ender; $H$. nitens $\quad$ Panamá,

Hort.; H. nana Colômbia,

Rodriguez; * $H$. Venezuela,

osaensis Cufod. var. Equador, Peru,

rubescens Stiles Brasil, Bolívia

Costa Rica,

Nicarágua,

Panamá,

Colômbia

Costa Rica,

Nicarágua 
Tabela 3. continuação

\begin{tabular}{|c|c|c|c|c|}
\hline Espécie & $\begin{array}{l}\text { Referência da } \\
\text { descrição }\end{array}$ & Sinonímia & Ocorrência natural & $\begin{array}{l}\text { Cultivares } \\
\text { comerciais }\end{array}$ \\
\hline $\begin{array}{l}\text { Heliconia pardoi } \\
\text { Abalo \& Morales }\end{array}$ & $\begin{array}{l}\text { ABALO \& } \\
\text { MORALES (1991) }\end{array}$ & & $\begin{array}{l}\text { Equador } \\
\text { (endêmica) }\end{array}$ & \\
\hline $\begin{array}{l}\text { Heliconia sanctae- } \\
\text { martae Andersson }\end{array}$ & $\begin{array}{l}\text { ANDERSSON } \\
\text { (1985a) }\end{array}$ & & $\begin{array}{l}\text { Colômbia } \\
\text { (endêmica) }\end{array}$ & \\
\hline $\begin{array}{l}\text { Heliconia subulata } \\
\text { Andersson; Heliconia } \\
\text { subulata Ruiz \& } \\
\text { Pavón subsp. } \\
\text { Subulata; Heliconia } \\
\text { subulata R. \& P subsp. } \\
\text { gracilis Andersson }\end{array}$ & $\begin{array}{l}\text { Ruiz \& Pavón, } \\
\text { 1802, citados por } \\
\text { ANDERSSON } \\
\text { (1985b) } \\
\text { ANDERSSON } \\
\text { (1985b) }\end{array}$ & $\begin{array}{l}\text { H. subulata Ruiz \& Pavón - H. } \\
\text { psittacorum L. f. var. subulata (R \& } \\
\text { P.) Baker; H. pearcei Rusby; H. } \\
\text { affinis Loes. H. psittacorum var. } \\
\text { gracilis Petersen; H. burchelli Baker } \\
\text { - Bihai burchelli (Baker) Griggs }\end{array}$ & $\begin{array}{l}\text { Equador, Peru, } \\
\text { Bolívia, Brasil, } \\
\text { Paraguai, } \\
\text { Argentina }\end{array}$ & Africa \\
\hline $\begin{array}{l}\text { Heliconia vaginalis } \\
\text { Benth.; Heliconia } \\
\text { vaginalis Benth. } \\
\text { subsp. mathiasiae } \\
\text { (Daniels \& Stiles); } \\
\text { Anders.; Heliconia } \\
\text { vaginalis Benth. } \\
\text { subsp. vaginalis }\end{array}$ & $\begin{array}{l}\text { Bentham 1844, } \\
\text { citado por } \\
\text { ANDERSSON } \\
(1985 \mathrm{~b}) \\
\text { ANDERSSON } \\
(1985 \mathrm{~b})\end{array}$ & $\begin{array}{l}H . \text { mathiasii Daniels \& Stiles; } H \text {. } \\
\text { golfodulcensis Daniels \& Stiles; } H \text {. } \\
\text { wilsonii Daniels \& Stiles; } H \text {. subulata } \\
\text { auct. non R. \& P; } H \text {. vaginalis } \\
\text { Bentham; } H \text {. deflexa Daniels \& Stiles; } \\
\text { H. subulata auct. non R. \& P. }\end{array}$ & $\begin{array}{l}\text { México, } \\
\text { Guatemala, Belize, } \\
\text { Honduras, } \\
\text { Nicaragua, Costa } \\
\text { Rica,Panamá, } \\
\text { Colômbia, Equador }\end{array}$ & $\begin{array}{l}\text { Purple } \\
\text { Flat; } \\
\text { Mildred; } \\
\text { Pacal; } \\
\text { Africa }\end{array}$ \\
\hline $\begin{array}{l}\text { Heliconia venusta } \\
\text { Abalo \& Morales }\end{array}$ & $\begin{array}{l}\text { ABALO \& } \\
\text { MORALES (1982) }\end{array}$ & H. montana Abalo \& Morales & Colômbia, Equador & \\
\hline \multicolumn{5}{|c|}{ Secção Zingiberastrum L. Anderss. } \\
\hline $\begin{array}{l}\text { Heliconia apparicioi } \\
\text { Barreiros }\end{array}$ & $\begin{array}{l}\text { BARREIROS } \\
(1976)\end{array}$ & & $\begin{array}{l}\text { Equador, Peru, } \\
\text { Brasil }\end{array}$ & \\
\hline $\begin{array}{l}\text { Heliconia aurantiaca } \\
\text { Ghiesb ex Lamaire }\end{array}$ & $\begin{array}{l}\text { Lamaire, 1862, } \\
\text { citado por } \\
\text { ANDERSSON } \\
(1985 a)\end{array}$ & $\begin{array}{l}\text { Bihai aurantiaca (Ghiesbr. Ex } \\
\text { Lemaire) Griggs - H. aurea Linden } \\
\text { ex Lemaire; } H \text {. brevispatha Hooker ; } \\
\text { H. choconiana Watson - Bihai } \\
\text { choconiana (Watson) Griggs; } H \text {. } \\
\text { crassa auct. non Griggs; } H \text {. } \\
\text { psittacorum auct. non L. f. }\end{array}$ & $\begin{array}{l}\text { México, Belize, } \\
\text { Guatemala, } \\
\text { Honduras, } \\
\text { Nicaragua, Costa } \\
\text { Rica }\end{array}$ & \\
\hline $\begin{array}{l}\text { Heliconia cordata } \\
\text { Andersson }\end{array}$ & $\begin{array}{l}\text { ANDERSSON } \\
(1985 b)\end{array}$ & & Colômbia, Equador & \\
\hline $\begin{array}{l}\text { Heliconia crassa } \\
\text { Griggs }\end{array}$ & GRIGGS (1903) & Bihai crassa (Griggs) Griggs & $\begin{array}{l}\text { Guatemala } \\
\text { (endêmica) }\end{array}$ & \\
\hline Heliconia hirsuta L. & $\begin{array}{l}\text { Lineu, 1781, citado } \\
\text { por ANDERSSON } \\
(1985 a)\end{array}$ & $\begin{array}{l}\text { Bihai hirsuta (L. f.) Kuntze; } H \text {. } \\
\text { bicolor Klotzsch non Bentham; } H \text {. } \\
\text { cannoidea L.C.Rich. var. villosa } \\
\text { Petersen; Bihai straminea Griggs - H. } \\
\text { straminea (Griggs) Standley; } H \text {. } \\
\text { hirsuta L. f. var. villosula Loesener; } \\
\text { Bihai harrisiana Griggs - H. } \\
\text { harrisiana (Griggs) L. B. Smith; } H \text {. } \\
\text { cardenasii L. B. Smith; H. burle- } \\
\text { marxii Emygdio; H. costanensis } \\
\text { Aristeguieta; H. hirsuta L.F. var. } \\
\text { villosa (Peters.) Lane f. laxa Barreiros } \\
\text { - nom. invalid.; H. hirsuta L. f. var. } \\
\text { glabra Barreiros f. magnifolia Lane } \\
\text { ex Barreiros - nom. invalid.; H. } \\
\text { hirsuta L. f. var. glabra Barreiros f. } \\
\text { laxa Barreiros - nom. inval.; H. } \\
\text { hirsuta L. f. var. glabra Barreiros f. } \\
\text { valida Barreiros - nom. invalid.; } \\
\text { H.hirsuta L.f. var. rubiflora } \\
\text { R.R.Smith; H. cararensis Abalo \& } \\
\text { Morales; H. psittacorum auct. non } \\
\text { L.f. }\end{array}$ & $\begin{array}{l}\text { Jamaica, St. } \\
\text { Vincent, Tobago, } \\
\text { Trinidad, Belize, } \\
\text { Honduras, } \\
\text { Nicaragua, } \\
\text { Panamá, } \\
\text { Colômbia, } \\
\text { Venezuela, } \\
\text { Guiana, Suriname, } \\
\text { Guiana Francesa, } \\
\text { Brasil, Equador, } \\
\text { Peru, Bolivia, } \\
\text { Paraguai, } \\
\text { Argentina }\end{array}$ & \\
\hline
\end{tabular}


Tabela 3. conclusão

\begin{tabular}{|c|c|c|c|c|}
\hline Espécie & $\begin{array}{l}\text { Referência da } \\
\text { descrição }\end{array}$ & Sinonímia & Ocorrência natural & $\begin{array}{l}\text { Cultivares } \\
\text { comerciais }\end{array}$ \\
\hline $\begin{array}{l}\text { Heliconia longiflora R. R. } \\
\text { Smith; Heliconia } \\
\text { longiflora R. R. Smith } \\
\text { subsp. Longiflora; } \\
\text { Heliconia longiflora R. R. } \\
\text { Smith subsp. ecuadorensis } \\
\text { Andersson }\end{array}$ & $\begin{array}{l}\text { SMITH (1977) } \\
\text { ANDERSSON } \\
(1985 b) \\
\text { ANDERSSON } \\
(1985 b)\end{array}$ & $\begin{array}{l}\text { H. longiflora } \\
\text { R.R.Smith }\end{array}$ & $\begin{array}{l}\text { Nicarágua, Costa Rica, } \\
\text { Panamá, Colômbia e } \\
\text { Equador }\end{array}$ & \\
\hline $\begin{array}{l}\text { Heliconia schumanniana } \\
\text { Loes. }\end{array}$ & $\begin{array}{l}\text { Loesener, 1916, citado } \\
\text { por ANDERSSON } \\
(1985 b)\end{array}$ & $\begin{array}{l}H . \\
\text { schumannia } \\
\text { na Loes. var. } \\
\text { basirubra } \\
\text { Loes. }\end{array}$ & $\begin{array}{l}\text { Equador, Colômbia, } \\
\text { Equador, Peru }\end{array}$ & Orange; White \\
\hline $\begin{array}{l}\text { Heliconia tarcarcunae } \\
\text { Andersson }\end{array}$ & $\begin{array}{l}\text { ANDERSSON } \\
\text { (1985a) }\end{array}$ & & Panamá, Colômbia & \\
\hline
\end{tabular}

* espécies onde exitem divergências entre taxonomistas

Tabela 4. Espécies, sinonímia, ocorrência natural e variedades/cultivares de helicônias do subgênero Heliconiopsis (Miq.) Kress

\begin{tabular}{|c|c|c|c|c|}
\hline Espécie & $\begin{array}{l}\text { Referência da } \\
\text { descrição }\end{array}$ & Sinonímia & Ocorrência natural & Cultivares comerciais \\
\hline $\begin{array}{l}\text { Heliconia indica Lam.; } \\
\text { Heliconia indica Lam. var. } \\
\text { indica; Heliconia indica } \\
\text { Lam. var. rubricarpa Kress; } \\
\text { Heliconia indica Lam. var. } \\
\text { dennisiana Kress; Heliconia } \\
\text { indica Lam. var. micholitzii } \\
\text { (Ridley) Kress; Heliconia } \\
\text { indica Lam. var. } \\
\text { austrocaledonica (Viell.) } \\
\text { Kress }\end{array}$ & $\begin{array}{l}\text { Lamarck, 1783, } \\
\text { citado por } \\
\text { KRESS (1990); } \\
\text { KRESS (1990) }\end{array}$ & $\begin{array}{l}\text { H. buccinata Roxb.; } \\
\text { Heliconiopsis } \\
\text { amboinensis Miq.; } H \text {. } \\
\text { indica var. bakeri } \\
\text { Lane ex Barreiros; } H . \\
\text { micholitzii Ridley; } H \text {. } \\
\text { austrocaledonica } \\
\text { Viell. }\end{array}$ & $\begin{array}{l}\text { Molucas, Nova } \\
\text { Guiné, Ilhas } \\
\text { Salomão, Nova } \\
\text { Caledônia, } \\
\text { Vanatu, Indonésia, } \\
\text { Sulawesi,Papua } \\
\text { Nova Guiné, Ilhas } \\
\text { Salomão, Nova } \\
\text { Caledônia }\end{array}$ & $\begin{array}{l}\text { Rabaul; Sanderi; } \\
\text { Seemannii; } \\
\text { Spectabilis; Edwardus- } \\
\text { rex; Illustris; } \\
\text { Roseostriata; Rubra; } \\
\text { Rubricaullis; Rubro- } \\
\text { striata; Striata; Viridis; } \\
\text { Domestica; Denisiana; } \\
\text { New Georgia }\end{array}$ \\
\hline $\begin{array}{l}\text { Heliconia lanata (P. Greis) } \\
\text { Kress }\end{array}$ & KRESS (1990) & $\begin{array}{l}\text { H. indica var. lanata } \\
\text { P. Green }\end{array}$ & $\begin{array}{l}\text { Ilhas Salomão } \\
\text { (endêmica) }\end{array}$ & \\
\hline Heliconia laufao Kress & KRESS (1990) & & Samoa (endêmica) & Dark; Light \\
\hline Heliconia paka A. C. Smith & SMITH (1967) & & Fiji (endêmica) & \\
\hline Heliconia papuana Kress & KRESS (1990) & & $\begin{array}{l}\text { Indonésia, Papua } \\
\text { Nova Guiné }\end{array}$ & \\
\hline $\begin{array}{l}\text { Heliconia solomonensis } \\
\text { Kress }\end{array}$ & KRESS (1990) & & $\begin{array}{l}\text { Ilhas Salomão, } \\
\text { Papua Nova Guiné }\end{array}$ & \\
\hline
\end{tabular}


Tabela 5. Espécies, sinonímia, ocorrência natural e variedades/cultivares de helicônias do subgênero Griggsia L. Anderss

\begin{tabular}{|c|c|c|c|c|}
\hline Espécie & Referência da descrição & Sinonímia & Ocorrência natural & $\begin{array}{l}\text { Cultivares } \\
\text { comerciais }\end{array}$ \\
\hline \multicolumn{5}{|l|}{ Seção Griggsia W. J. Kress } \\
\hline $\begin{array}{l}\text { Heliconia gigantea Kress e } \\
\text { Betancur }\end{array}$ & KRESS et al. (1993) & & Colômbia (endêmica) & \\
\hline $\begin{array}{l}\text { Heliconia griggsiana L. B. } \\
\text { Smith }\end{array}$ & $\begin{array}{l}\text { Smith, 1939, citado por } \\
\text { ANDERSSON (1985b) }\end{array}$ & & Colômbia, Equador & $\begin{array}{l}\text { Angry } \\
\text { Moon; } \\
\text { Blue } \\
\text { Moon }\end{array}$ \\
\hline $\begin{array}{l}\text { Heliconia griggsiana L. B. } \\
\text { Smith var. boultoniana } \\
\text { Abalo e Morales }\end{array}$ & & $\begin{array}{l}\text { H. boultoniana Abalo } \\
\text { e Morales }\end{array}$ & Colômbia & \\
\hline $\begin{array}{l}\text { Heliconia griggsiana L. B. } \\
\text { Smith var. tandayapensis } \\
\text { Abalo e Morales }\end{array}$ & & $\begin{array}{l}\text { H. tandayapensis } \\
\text { Abalo e Morales }\end{array}$ & Equador & \\
\hline $\begin{array}{l}\text { Heliconia paludigena Abalo } \\
\text { e Morales }\end{array}$ & $\begin{array}{l}\text { ABALO e MORALES } \\
\text { (1983a) }\end{array}$ & $\begin{array}{l}\text { H. angelica Abalo e } \\
\text { Morales }\end{array}$ & Equador (endêmica) & \\
\hline $\begin{array}{l}\text { Heliconia pastazae } \\
\text { Andersson }\end{array}$ & ANDERSSON (1985b) & & Equador (endêmica) & \\
\hline $\begin{array}{l}\text { Heliconia titanum Kress e } \\
\text { Betancur }\end{array}$ & KRESS et al. (1993) & & Colômbia (endêmica) & \\
\hline
\end{tabular}

\begin{tabular}{|c|c|c|c|}
\hline Seção Barbatae W. J. Kress & & & \\
\hline Heliconia danielsiana Kress & KRESS (1984) & $\begin{array}{l}\text { H. vellerigera auct. } \\
\text { non Poeppig }\end{array}$ & Costa Rica (endêmica) \\
\hline Heliconia lutheri Kress & KRESS (1992) & & Equador (endêmica) \\
\hline Heliconia magnifica Kress & KRESS (1981) & $\begin{array}{l}\text { H. vellerigera auct. } \\
\text { non Poeppig }\end{array}$ & Panamá (endêmica) \\
\hline $\begin{array}{l}\text { Heliconia markiana Abalo e } \\
\text { Morales }\end{array}$ & $\begin{array}{l}\text { ABALO e MORALES } \\
\text { (1991) }\end{array}$ & & Equador (endêmica) \\
\hline $\begin{array}{l}\text { Heliconia peteriana Abalo e } \\
\text { Morales }\end{array}$ & $\begin{array}{l}\text { ABALO e MORALES } \\
\text { (1991) }\end{array}$ & & Equador (endêmica) \\
\hline Heliconia pogonantha Cuf. & $\begin{array}{l}\text { Cufodontes, 1933, citado por } \\
\text { KRESS (1984) }\end{array}$ & & $\begin{array}{l}\text { Costa Rica, Nicaragua, } \\
\text { Panamá }\end{array}$ \\
\hline $\begin{array}{l}\text { Heliconia pogonantha Cuf. } \\
\text { var. holerythra Daniels e } \\
\text { Stiles }\end{array}$ & DANIELS e STILES (1979) & & $\begin{array}{l}\text { Costa Rica, Panamá, } \\
\text { Colômbia }\end{array}$ \\
\hline $\begin{array}{l}\text { Heliconia pogonantha Cuf. } \\
\text { var. pubescens }\end{array}$ & DANIELS e STILES (1979) & & Costa Rica \\
\hline $\begin{array}{l}\text { Heliconia pogonantha Cuf. } \\
\text { var. pogonantha }\end{array}$ & DANIELS e STILES (1979) & & Nicaragua, Costa Rica \\
\hline $\begin{array}{l}\text { Heliconia pogonantha } \\
\text { Cufod. var. veraguasensis } \\
\text { Kress }\end{array}$ & KRESS (1981) & & Panamá (endêmica) \\
\hline $\begin{array}{l}\text { H. ramonensis Daniels e } \\
\text { Stiles }\end{array}$ & DANIELS e STILES (1979) & & Costa Rica, Panamá \\
\hline $\begin{array}{l}\text { H. ramonensis Daniels e } \\
\text { Stiles var glabra Kress }\end{array}$ & KRESS (1984) & & Panamá \\
\hline $\begin{array}{l}\text { H. ramonensis Daniels e } \\
\text { Stiles var. ramonensi }\end{array}$ & DANIELS e STILES (1979) & & Panamá \\
\hline $\begin{array}{l}\text { H. ramonensis Daniels e } \\
\text { Stiles var. ramonensis }\end{array}$ & DANIELS e STILES (1979) & & Costa Rica \\
\hline
\end{tabular}


Tabela 5. continuação

\begin{tabular}{|c|c|c|c|c|}
\hline Espécie & $\begin{array}{l}\text { Referência da } \\
\text { descrição }\end{array}$ & Sinonímia & $\begin{array}{l}\text { Ocorrência } \\
\text { natural }\end{array}$ & $\begin{array}{l}\text { Cultivares } \\
\text { comerciais }\end{array}$ \\
\hline $\begin{array}{l}\text { H. ramonensis } \\
\text { Daniels e Stiles var. } \\
\text { lanuginosa Kress }\end{array}$ & KRESS (1984) & & Panamá & \\
\hline $\begin{array}{l}\text { H. ramonensis } \\
\text { Daniels e Stiles var. } \\
\text { xanthotricha Kress }\end{array}$ & KRESS (1981) & $\begin{array}{l}\text { H. vellerigera auct. non } \\
\text { Poeppig }\end{array}$ & Panamá & \\
\hline $\begin{array}{l}\text { Heliconia regalis } \\
\text { Andersson }\end{array}$ & ANDERSSON (1985b) & & $\begin{array}{l}\text { Equador, } \\
\text { Colômbia }\end{array}$ & \\
\hline $\begin{array}{l}\text { Heliconia rhodantha } \\
\text { Abalo e Morales }\end{array}$ & $\begin{array}{l}\text { ABALO e MORALES } \\
\text { (1982) }\end{array}$ & & $\begin{array}{l}\text { Colômbia } \\
\text { (endêmica) }\end{array}$ & \\
\hline $\begin{array}{l}\text { Heliconia sanctae- } \\
\text { theresae Abalo e } \\
\text { Morales }\end{array}$ & $\begin{array}{l}\text { ABALO e MORALES } \\
\text { (1985) }\end{array}$ & & $\begin{array}{l}\text { Colômbia } \\
\text { (endêmica) }\end{array}$ & \\
\hline $\begin{array}{l}\text { Heliconia } \\
\text { vellerigera Poep. }\end{array}$ & $\begin{array}{l}\text { Poeppings, 1836, } \\
\text { citado por } \\
\text { ANDERSSON (1985b) }\end{array}$ & $\begin{array}{l}\text { Bihai vellerigera (Poepp.) } \\
\text { KUNTZE }\end{array}$ & $\begin{array}{l}\text { Peru, Colômbia, } \\
\text { Equador }\end{array}$ & King Kong \\
\hline $\begin{array}{l}\text { Heliconia } \\
\text { xanthovillosa Kress }\end{array}$ & KRESS (1981) & $\begin{array}{l}\text { H. dresslerana Abalo e } \\
\text { Morales }\end{array}$ & $\begin{array}{l}\text { Panamá, } \\
\text { Colômbia }\end{array}$ & Shogun \\
\hline
\end{tabular}

Seção Longae W. J. Kress

H. excelsa
Andersson
Heliconia harlingii
Andersson
Heliconia longa
(Griggs) Weinkler

Heliconia mariae Hook.

\section{ANDERSSON (1985a)}

ANDERSSON (1985b)

WINKLER (1930)

Hooker, 1864, citado por KRESS (1984)
Equador (endêmica)

Equador (endêmica)

Bihai longa Griggs;

Equador, Costa

H. stilesii Kress;

H. curtispatha auct. non Peters.

Rica, Colômbia, Nicarágua.

Panamá

Bihai mariae (Hooker)

Kuntze;

H. elegans Petersen -

Belize,

Guatemala,

Honduras,

Bihai elegans (Petersen)

Kuntze;

Nicaragua, Costa

Rica, Panamá,

Bihai punicea Griggs - $H$. Colômbia,

punicea (Griggs) Venezuela

L.B.Smith
H. stilesii Kress

Kress, 1982 citado por KRESS (1984)
Costa Rica, Panamá

Seção Pendulae (Griggs) W. J. Kress

Heliconia chartacea
Lane ex Barreiros

Lane ex Barreiros

\begin{abstract}
chartaceae Lane ex
Souza Barreiros var.
\end{abstract}

Heliconia

chartacea

Heliconia

chartaceae Lane ex

Souza Barreiros var.

meeana Kress

KRESS (1977)

KRESS (1997)
Brasil, Guiana,

Suriname,

Sexy Pink; Sexy

Scarlet; Equador;

Guiana Francesa, Maroon; Meeana

Equador,

Colômbia

H. meeana Kress

Venezuela 
Tabela 5. continuação

\begin{tabular}{|c|c|c|c|c|}
\hline Espécie & $\begin{array}{l}\text { Referência da } \\
\text { descrição }\end{array}$ & Sinonímia & Ocorrência natural & $\begin{array}{l}\text { Cultivares } \\
\text { comerciais }\end{array}$ \\
\hline $\begin{array}{l}\text { Heliconia } \\
\text { collinsiana Griggs }\end{array}$ & GRIGGS (1903) & $\begin{array}{l}\text { Bihai collinsiana (Griggs) } \\
\text { Griggs; } \\
\text { H. rostrata auct. non Ruiz } \\
\text { e Pavón }\end{array}$ & Nicaragua, México & \\
\hline $\begin{array}{l}\text { Heliconia } \\
\text { collinsiana Griggs } \\
\text { var. collinsiana }\end{array}$ & KRESS (1984) & & $\begin{array}{l}\text { México, Guatemala, } \\
\text { Belize, El Salvador, }\end{array}$ & \\
\hline $\begin{array}{l}\text { Heliconia } \\
\text { collinsiana Griggs } \\
\text { var. velutina Kress }\end{array}$ & KRESS (1984) & & $\begin{array}{l}\text { Honduras, Nicaragua } \\
\text { Guatemala, El } \\
\text { Salvador }\end{array}$ & \\
\hline $\begin{array}{l}\text { Heliconia } \\
\text { collinsiana Griggs } \\
\text { var. velutina Kress }\end{array}$ & KRESS (1981) & & $\begin{array}{l}\text { Guatemala e El } \\
\text { Salvador }\end{array}$ & \\
\hline $\begin{array}{l}\text { Heliconia } \\
\text { fernandezii Abalo e } \\
\text { Morales }\end{array}$ & $\begin{array}{l}\text { ABALO e MORALES } \\
\text { (1982) }\end{array}$ & $\begin{array}{l}H . \text { griggsiana L. B. Smith } \\
\text { var. fernandezii Abalo e } \\
\text { Morales }\end{array}$ & Colômbia (endêmica) & \\
\hline $\begin{array}{l}\text { Heliconia mooreana } \\
\text { R. R. Smith }\end{array}$ & SMITH (1989) & & México (endêmica) & \\
\hline $\begin{array}{l}\text { Heliconia pendula } \\
\text { Wawra }\end{array}$ & $\begin{array}{l}\text { Wawra, 1863, citado } \\
\text { por BARREIROS } \\
(1972)\end{array}$ & H. steyermarkii Aristeg. & $\begin{array}{l}\text { Brasil, Venezuela, } \\
\text { Colômbia, Panamá, } \\
\text { Guatemala, Trinidad }\end{array}$ & $\begin{array}{l}\text { Bright Red; } \\
\text { Frosty; Red } \\
\text { Waxy; } \\
\text { Atlantica; } \\
\text { Styermarkii }\end{array}$ \\
\hline $\begin{array}{l}\text { Heliconia } \\
\text { platystachys Baker }\end{array}$ & $\begin{array}{l}\text { Baker, 1893, citado por } \\
\text { KRESS (1984) }\end{array}$ & $\begin{array}{l}\text { Bihai platystachys (Baker) } \\
\text { Griggs; } \\
\text { H. catheta R.R.Smith }\end{array}$ & $\begin{array}{l}\text { Costa Rica, Panamá, } \\
\text { Guiana, Suriname, } \\
\text { Guianar Francesa, } \\
\text { Colômbia, Venezuela }\end{array}$ & \\
\hline $\begin{array}{l}\text { Heliconia rigida } \\
\text { Abalo e Morales }\end{array}$ & $\begin{array}{l}\text { ABALO e MORALES } \\
\text { (1982) }\end{array}$ & & Colômbia (endêmica) & \\
\hline $\begin{array}{l}\text { Heliconia } \\
\text { riopalenquensis } \\
\text { Dodson e Gentry }\end{array}$ & $\begin{array}{l}\text { DODSON e GENTRY } \\
(1978)\end{array}$ & & Equador (endêmica) & \\
\hline Heliconia villosa $\mathrm{Kl}$. & $\begin{array}{l}\text { Klotzsch, 1847, citado } \\
\text { por ARISTEGUIETA } \\
(1961)\end{array}$ & $\begin{array}{l}\text { H.dasyantha K. Koch e } \\
\text { Bouché; Bihai villosa } \\
\text { (Klotzsch) O. Kuntze; } \\
\text { Bihaia dasyantha (K. } \\
\text { Koch e Bouché) O. Ktze. } \\
\text { H.tortuosa Griggs: - } \\
\text { Bihaia tortuosa Griggs }\end{array}$ & $\begin{array}{l}\text { Venezuela, Colômbia, } \\
\text { Panamá }\end{array}$ & \\
\hline
\end{tabular}

Seção Rostratae W. J. Kress

\begin{tabular}{llll}
\hline $\begin{array}{l}\text { Heliconia flabellata } \\
\text { Abalo e Morales }\end{array}$ & $\begin{array}{l}\text { ABALO e MORALES } \\
\text { (1983a) }\end{array}$ & & $\begin{array}{l}\text { Equador, } \\
\text { Colômbia }\end{array}$ \\
$\begin{array}{l}\text { Heliconia juruana } \\
\text { Loes }\end{array}$ & $\begin{array}{l}\text { Loesener, 1916, citado } \\
\text { por ANDERSSON } \\
\text { (1985b) }\end{array}$ & H. triflora Barreiros & $\begin{array}{l}\text { Brasil, } \\
\text { Colômbia, } \\
\text { Equador }\end{array}$ \\
$\begin{array}{l}\text { Heliconia marginata } \\
\text { (Griggs) Pittier }\end{array}$ & $\begin{array}{l}\text { Pittier, 1926, citado por } \\
\text { ANDERSSON (1985b) }\end{array}$ & $\begin{array}{l}\text { Bihai marginata Griggs; } \\
\text { H. marginata (Griggs) } \\
\text { Pittier f. lutea }\end{array}$ & $\begin{array}{l}\text { Panamá, } \\
\text { Venezuela, Costa } \\
\text { Rica, Colômbia, } \\
\text { Peru, Brasil, } \\
\text { Guiana Francesa. }\end{array}$ \\
& & & Suriname \\
\hline
\end{tabular}


Tabela 5. continuação

\begin{tabular}{|c|c|c|c|c|}
\hline Espécie & $\begin{array}{l}\text { Referência da } \\
\text { descrição }\end{array}$ & Sinonímia & $\begin{array}{l}\text { Ocorrência } \\
\text { natural }\end{array}$ & $\begin{array}{l}\text { Cultivares } \\
\text { comerciais }\end{array}$ \\
\hline $\begin{array}{l}\text { Heliconia } \\
\text { rauliniana } \\
\text { Barreiros }\end{array}$ & BARREIROS (1974) & & $\begin{array}{l}\text { Venezuela, } \\
\text { Brasil }\end{array}$ & \\
\hline $\begin{array}{l}\text { Heliconia rostrata } \\
\text { Ruiz e Pavón }\end{array}$ & $\begin{array}{l}\text { Ruiz e Pavón, 1802, } \\
\text { citado por } \\
\text { ANDERSSON } \\
(1985 b)\end{array}$ & $\begin{array}{l}\text { Bihai rostrata (R.e P.) } \\
\text { Griggs; } \\
\text { H. poeppigiana Petersen } \\
\text { - Bihai poeppigiana } \\
\text { (Peters.) Kuntze }\end{array}$ & $\begin{array}{l}\text { Equador, } \\
\text { Colômbia, } \\
\text { Brasil, Peru, } \\
\text { Bolívia }\end{array}$ & $\begin{array}{l}\text { Twirl; Giant; } \\
\text { Dwarf; Misahualli; } \\
\text { Pink Peru; Sun- } \\
\text { kissed Orange }\end{array}$ \\
\hline $\begin{array}{l}\text { Heliconia standleyi } \\
\text { Macbrid. }\end{array}$ & MACBRIDE (1931) & & $\begin{array}{l}\text { Peru, Colômbia, } \\
\text { Equador, Brasil }\end{array}$ & \\
\hline \multicolumn{5}{|c|}{ Seção Sigmoideae W. J. Kress } \\
\hline $\begin{array}{l}\text { Heliconia badilloi } \\
\text { Abalo e Morales }\end{array}$ & $\begin{array}{l}\text { ABALO e MORALES } \\
(1983 b)\end{array}$ & & $\begin{array}{l}\text { Colômbia } \\
\text { (endêmica) }\end{array}$ & \\
\hline $\begin{array}{l}\text { Heliconia } \\
\text { berriziana Abalo e } \\
\text { Morales }\end{array}$ & $\begin{array}{l}\text { ABALO e MORALES } \\
\text { (1985) }\end{array}$ & & $\begin{array}{l}\text { Colômbia } \\
\text { (endêmica) }\end{array}$ & \\
\hline $\begin{array}{l}\text { Heliconia } \\
\text { caquetensis Abalo e } \\
\text { Morales }\end{array}$ & $\begin{array}{l}\text { ABALO e MORALES } \\
(1982)\end{array}$ & & $\begin{array}{l}\text { Colômbia } \\
\text { (endêmica) }\end{array}$ & \\
\hline $\begin{array}{l}\text { Heliconia colgantea } \\
\text { R.R.Smith ex Dan. } \\
\text { e Stiles }\end{array}$ & $\begin{array}{l}\text { DANIELS e STILES } \\
(1979)\end{array}$ & & $\begin{array}{l}\text { Costa Rica, } \\
\text { Panamá, } \\
\text { Colômbia }\end{array}$ & \\
\hline $\begin{array}{l}\text { Heliconia dielsiana } \\
\text { Loes }\end{array}$ & DIELS (1937) & $\begin{array}{l}\text { H. andina Abalo e } \\
\text { Morales }\end{array}$ & $\begin{array}{l}\text { Colômbia, } \\
\text { Equador }\end{array}$ & \\
\hline $\begin{array}{l}\text { Heliconia } \\
\text { intermedia Abalo e } \\
\text { Morales }\end{array}$ & $\begin{array}{l}\text { ABALO e MORALES } \\
(1983 b)\end{array}$ & & $\begin{array}{l}\text { Colômbia } \\
\text { (endêmica) }\end{array}$ & \\
\hline $\begin{array}{l}\text { Heliconia } \\
\text { lentiginosa Abalo e } \\
\text { Morales }\end{array}$ & $\begin{array}{l}\text { ABALO e MORALES } \\
\text { (1985) }\end{array}$ & & $\begin{array}{l}\text { Colômbia } \\
\text { (endêmica) }\end{array}$ & \\
\hline $\begin{array}{l}\text { Heliconia maculata } \\
\text { Kress }\end{array}$ & KRESS (1981) & & $\begin{array}{l}\text { Panamá } \\
\text { (endêmica) }\end{array}$ & \\
\hline $\begin{array}{l}\text { Heliconia } \\
\text { necrobracteata } \\
\text { Kress }\end{array}$ & KRESS (1981) & & $\begin{array}{l}\text { Panamá } \\
\text { (endêmica) }\end{array}$ & \\
\hline $\begin{array}{l}\text { Heliconia oleosa } \\
\text { Abalo e Morales }\end{array}$ & $\begin{array}{l}\text { ABALO e MORALES } \\
\text { (1982) }\end{array}$ & & $\begin{array}{l}\text { Colômbia } \\
\text { (endêmica) }\end{array}$ & \\
\hline $\begin{array}{l}\text { Heliconia } \\
\text { penduloides Loes. }\end{array}$ & $\begin{array}{l}\text { Loesener, 1916, citado } \\
\text { por BARREIROS } \\
(1972,1979)\end{array}$ & & Colômbia, Peru & \\
\hline $\begin{array}{l}\text { Heliconia reptans } \\
\text { Abalo e Morales }\end{array}$ & $\begin{array}{l}\text { ABALO e MORALES } \\
\text { (1982) }\end{array}$ & & $\begin{array}{l}\text { Colômbia } \\
\text { (endêmica }\end{array}$ & \\
\hline $\begin{array}{l}\text { Heliconia robertoi } \\
\text { Abalo e Morales }\end{array}$ & $\begin{array}{l}\text { ABALO e MORALES } \\
\text { (1985) }\end{array}$ & & $\begin{array}{l}\text { Colômbia } \\
\text { (endêmica) }\end{array}$ & \\
\hline $\begin{array}{l}\text { Heliconia } \\
\text { sclerotricha Abalo e } \\
\text { Morales }\end{array}$ & $\begin{array}{l}\text { ABALO e MORALES } \\
\text { (1983a) }\end{array}$ & & $\begin{array}{l}\text { Equador } \\
\text { (endêmica) }\end{array}$ & \\
\hline $\begin{array}{l}\text { Heliconia signa- } \\
\text { hispanica Abalo e } \\
\text { Morales }\end{array}$ & $\begin{array}{l}\text { ABALO e MORALES } \\
\text { (1983b) }\end{array}$ & & $\begin{array}{l}\text { Colômbia } \\
\text { (endêmica) }\end{array}$ & \\
\hline
\end{tabular}


Tabela 5. continuação

\begin{tabular}{|c|c|c|c|c|}
\hline Espécie & $\begin{array}{l}\text { Referência da } \\
\text { descrição }\end{array}$ & Sinonímia & $\begin{array}{l}\text { Ocorrência } \\
\text { natural }\end{array}$ & $\begin{array}{l}\text { Cultivares } \\
\text { comerciais }\end{array}$ \\
\hline $\begin{array}{l}\text { Heliconia } \\
\text { talamancana } \\
\text { Daniels e Stiles }\end{array}$ & $\begin{array}{l}\text { DANIELS e STILES } \\
\text { (1979) }\end{array}$ & & $\begin{array}{l}\text { Costa Rica, } \\
\text { Panamá }\end{array}$ & \\
\hline $\begin{array}{l}\text { Heliconia } \\
\text { trichocarpa Daniels } \\
\text { e Stiles }\end{array}$ & $\begin{array}{l}\text { DANIELS e STILES } \\
\text { (1979) }\end{array}$ & & $\begin{array}{l}\text { Costa Rica, } \\
\text { Panamá }\end{array}$ & \\
\hline \multicolumn{5}{|c|}{ Seção Obscurae W. J. Kress } \\
\hline $\begin{array}{l}\text { H. abaloi G. } \\
\text { Morales }\end{array}$ & MORALES (1984) & & $\begin{array}{l}\text { Colômbia } \\
\text { (endêmica) }\end{array}$ & \\
\hline $\begin{array}{l}\text { Heliconia } \\
\text { chrysocraspeda } \\
\text { Abalo e Morales }\end{array}$ & ABALO e MORALES (1982) & & $\begin{array}{l}\text { Colômbia } \\
\text { (endêmica) }\end{array}$ & \\
\hline $\begin{array}{l}\text { Heliconia } \\
\text { combinata Abalo e } \\
\text { Morales }\end{array}$ & ABALO e MORALES (1983b) & & $\begin{array}{l}\text { Colômbia } \\
\text { (endêmica) }\end{array}$ & \\
\hline $\begin{array}{l}\text { H. estiletioides } \\
\text { Abalo e Morales }\end{array}$ & ABALO e MORALES (1982) & & $\begin{array}{l}\text { Colômbia } \\
\text { (endêmica) }\end{array}$ & \\
\hline $\begin{array}{l}\text { Heliconia fragilis } \\
\text { Abalo e Morales }\end{array}$ & ABALO e MORALES (1982) & & $\begin{array}{l}\text { Colômbia, } \\
\text { Equador }\end{array}$ & \\
\hline $\begin{array}{l}\text { Heliconia } \\
\text { fredberryana Kress }\end{array}$ & KRESS (1992) & & $\begin{array}{l}\text { Equador } \\
\text { (endêmica) }\end{array}$ & \\
\hline $\begin{array}{l}\text { Heliconia laxa } \\
\text { Abalo e Morales }\end{array}$ & ABALO e MORALES (1982) & & $\begin{array}{l}\text { Colômbia } \\
\text { (endêmica) }\end{array}$ & \\
\hline $\begin{array}{l}\text { Heliconia lozanoi } \\
\text { Abalo e Morales }\end{array}$ & ABALO e MORALES (1985) & & $\begin{array}{l}\text { Colômbia } \\
\text { (endêmica) }\end{array}$ & \\
\hline $\begin{array}{l}\text { Heliconia mutisiana } \\
\text { Cuatrec }\end{array}$ & Citada por KRESS et al. (1999) & & $\begin{array}{l}\text { Colômbia } \\
\text { (endêmica) }\end{array}$ & \\
\hline $\begin{array}{l}\text { Heliconia } \\
\text { nariniensis Abalo e } \\
\text { Morales }\end{array}$ & ABALO e MORALES (1982) & & $\begin{array}{l}\text { Colômbia } \\
\text { (endêmica) }\end{array}$ & \\
\hline $\begin{array}{l}\text { Heliconia nitida } \\
\text { Abalo e Morales }\end{array}$ & ABALO e MORALES (1982) & & $\begin{array}{l}\text { Colômbia } \\
\text { (endêmica) }\end{array}$ & \\
\hline $\begin{array}{l}\text { Heliconia obscura } \\
\text { Dodson e Gentry }\end{array}$ & DODSON e GENTRY (1978) & $\begin{array}{l}\text { Heliconia obscura } \\
\text { Dodson e Gentry }\end{array}$ & $\begin{array}{l}\text { Equador } \\
\text { (endêmica) }\end{array}$ & Dichroma Red \\
\hline $\begin{array}{l}\text { Heliconia obscura } \\
\text { Dodson e Gentry } \\
\text { ssp. Obscura }\end{array}$ & ANDERSSON (1985ba) & & $\begin{array}{l}\text { Equador } \\
\text { (endêmica) }\end{array}$ & \\
\hline $\begin{array}{l}\text { Heliconia obscura } \\
\text { Dodson e Gentry } \\
\text { ssp. fusca } \\
\text { Andersson }\end{array}$ & & & $\begin{array}{l}\text { Equador } \\
\text { (endêmica) }\end{array}$ & \\
\hline $\begin{array}{l}\text { Heliconia } \\
\text { obscuroides } \\
\text { Andersson }\end{array}$ & ANDERSSON (1985b) & & $\begin{array}{l}\text { Colômbia, } \\
\text { Equador }\end{array}$ & \\
\hline $\begin{array}{l}\text { Heliconia robusta } \\
\text { Pax. }\end{array}$ & $\begin{array}{l}\text { Citação de } \\
\text { ANDERSSON (1985b) }\end{array}$ & & Bolívia, Peru & \\
\hline
\end{tabular}

Seção Contortex W. J. Kress

\begin{tabular}{llll}
\hline $\begin{array}{l}\text { Heliconia nutans R. } \\
\text { E. Woodson }\end{array}$ & Woodson, 1934 citado & $\begin{array}{l}\text { H. allenii Standley e Willians; } \\
\text { por KRESS (1984) }\end{array}$ & $\begin{array}{l}\text { Costa } \text {. villosa auct. non Klotzsch } \\
\text { Panamá }\end{array}$ \\
\hline
\end{tabular}


Tabela 5. continuação

\begin{tabular}{|c|c|c|c|c|}
\hline Espécie & $\begin{array}{l}\text { Referência da } \\
\text { descrição }\end{array}$ & Sinonímia & $\begin{array}{l}\text { Ocorrência } \\
\text { natural }\end{array}$ & $\begin{array}{l}\text { Cultivares } \\
\text { comerciais }\end{array}$ \\
\hline \multicolumn{5}{|c|}{ Seção Arcuatae W. J. Kress } \\
\hline $\begin{array}{l}\text { Heliconia } \\
\text { curtispatha Petersen }\end{array}$ & $\begin{array}{l}\text { Petersen, 1890, citado } \\
\text { por ANDERSSON } \\
(1985 b)\end{array}$ & $\begin{array}{l}\text { H. sessilis Kress } \\
\text { Bihaia curtispatha } \\
\text { (Petersen) Kuntze; } \\
\text { Bihai longa Griggs }-H \text {. } \\
\text { longa (Griggs) Winkler; } \\
\text { H. rostrata auct. non Ruiz } \\
\text { e Pavón }\end{array}$ & $\begin{array}{l}\text { Equador, } \\
\text { Panamá, } \\
\text { Colômbia }\end{array}$ & \\
\hline $\begin{array}{l}\text { Heliconia } \\
\text { nigripraefixa } \\
\text { Dodson e Gentry }\end{array}$ & $\begin{array}{l}\text { DODSON e GENTRY } \\
(1978)\end{array}$ & & $\begin{array}{l}\text { Equador, } \\
\text { Panamá, } \\
\text { Colômbia }\end{array}$ & \\
\hline \multicolumn{5}{|c|}{ Seção Dromedarius W. J. Kress } \\
\hline $\begin{array}{l}\text { Heliconia arrecta } \\
\text { Kress e Betancur }\end{array}$ & KRESS et. al. (1993) & & $\begin{array}{l}\text { Colômbia } \\
\text { (endêmica) }\end{array}$ & \\
\hline $\begin{array}{l}\text { Heliconia huilensis } \\
\text { Abalo e Morales }\end{array}$ & $\begin{array}{l}\text { ABALO e MORALES } \\
(1982)\end{array}$ & & $\begin{array}{l}\text { Colômbia } \\
\text { (endêmica) }\end{array}$ & \\
\hline $\begin{array}{l}\text { Heliconia } \\
\text { mucilagina Abalo e } \\
\text { Morales }\end{array}$ & $\begin{array}{l}\text { ABALO e MORALES } \\
\text { (1982) }\end{array}$ & & $\begin{array}{l}\text { Colômbia } \\
\text { (endêmica) }\end{array}$ & \\
\hline $\begin{array}{l}\text { Heliconia spiralis } \\
\text { Abalo e Morales }\end{array}$ & $\begin{array}{l}\text { ABALO e MORALES } \\
(1983 b)\end{array}$ & & $\begin{array}{l}\text { Colômbia } \\
\text { (endêmica }\end{array}$ & \\
\hline \multicolumn{5}{|c|}{ Seção Retiformes W. J. Kress } \\
\hline $\begin{array}{l}\text { Heliconia donstonea } \\
\text { Kress e Betancur }\end{array}$ & KRESS et al. (1993) & & $\begin{array}{l}\text { Colômbia, } \\
\text { Equador }\end{array}$ & \\
\hline $\begin{array}{l}\text { Heliconia } \\
\text { holmquistiana } \\
\text { Abalo e Morales }\end{array}$ & $\begin{array}{l}\text { ABALO e MORALES } \\
\text { (1991) }\end{array}$ & & $\begin{array}{l}\text { Colômbia } \\
\text { (endêmica) }\end{array}$ & \\
\hline $\begin{array}{l}\text { Heliconia stella- } \\
\text { maris Abalo e } \\
\text { Morales }\end{array}$ & $\begin{array}{l}\text { ABALO e MORALES } \\
(1983 b)\end{array}$ & & $\begin{array}{l}\text { Colômbia } \\
\text { (endêmica) }\end{array}$ & \\
\hline $\begin{array}{l}\text { Heliconia terciopela } \\
\text { Kress e Betancurt }\end{array}$ & KRESS et al. (1993) & & Peru (endêmica) & \\
\hline
\end{tabular}

* espécies onde exitem divergências entre taxonomistas 
Tabela 6. Outras espécies de helicônias descritas, não incluídas em floras regionais, revisões de gênero ou não consideradas sinonímias

\begin{tabular}{lll}
\hline \multicolumn{1}{c}{ Espécie } & \multicolumn{1}{c}{ Referência } & Local de ocorrência \\
\hline Heliconia auriculata Barreiros & BARREIROS (1980) & Brasil \\
Heliconia carajaensis & BARREIROS (1980) & Brasil \\
Heliconia carmelae Abalo e Morales & ABALO e MORALES (1982) & Colômbia \\
Heliconia cristata Barreiros & BARREIROS (1985) & Panamá \\
Heliconia litana Kress & KRESS (1992) & Equador \\
Heliconia longissima Abalo e Morales & ABALO e MORALES (1982) & Colômbia \\
Heliconia luciae Barreiros & BARREIROS (1993) & Brasil \\
Heliconia luteoviridis Abalo e Morales & ABALO e MORALES (1982) & Colômbia \\
Heliconia santaremensis Barreiros & BARREIROS (1980) & Brasil \\
Heliconia sucrei Barreiros & BARREIROS (1985) & Panamá \\
Heliconia tridentata Barreiros & BARREIROS (1976) & Colômbia \\
Heliconia uxpanapensis Báez & BÁEZ (1987) & México \\
\hline
\end{tabular}


Tabela 7. Híbridos naturais de helicônia descritos

\begin{tabular}{|c|c|c|c|}
\hline Hibrido & Referência & Sinonímia & Variedades comerciais \\
\hline H. episcopalis X rostrata & ANDERSSON (1985b) & $\begin{array}{l}\text { H. flabellata } \\
\text { Abalo e Morales }\end{array}$ & \\
\hline $\begin{array}{l}\text { H. latispatha } \mathrm{X} \\
\text { spathocircinata }\end{array}$ & ANDERSSON (1985b) & $\begin{array}{l}\text { H. plagiotropa } \\
\text { Abalo e Morales }\end{array}$ & \\
\hline $\begin{array}{l}\text { H. curtispatha } \mathrm{X} \\
\text { H.pogonantha var. holerythra }\end{array}$ & KRESS (1984) & & \\
\hline $\begin{array}{l}\text { H. mariae X H. pogonantha } \\
\text { var. holerythra }\end{array}$ & KRESS (1984) & & Bushmaster \\
\hline $\begin{array}{l}\text { H. nutans X H. lankesteri } \\
\text { var. rubra }\end{array}$ & KRESS (1984) & & \\
\hline $\begin{array}{l}\text { H. secunda var. secunda X } H \text {. } \\
\text { clinophila }\end{array}$ & KRESS (1984) & & \\
\hline H. stilesii X H. danielsiana & KRESS (1984) & & \\
\hline H. tortuosa X H. nutans & KRESS (1984) & & \\
\hline H. adflexa X H. collinsiana & ANDERSSON (1985a) & & \\
\hline $\begin{array}{l}\text { H. apparicioi X } H \text {. } \\
\text { schumanniana }\end{array}$ & ANDERSSON (1985a) & & \\
\hline H. cordata X H. longiflora & ANDERSSON (1985a) & & \\
\hline $\begin{array}{l}\text { H. longiflora ssp. } \\
\text { ecuadoriensis X H. latispatha }\end{array}$ & ANDERSSON (1985a) & & \\
\hline H. metallica X H. marginata & ANDERSSON (1985a) & & \\
\hline H.imbricata X H. latispatha & ANDERSSON (1992) & & José Abalo \\
\hline $\begin{array}{l}\text { H. imbricata X H. } \\
\text { sarapiquiensis }\end{array}$ & ANDERSSON (1992) & & Harvey Bulls \\
\hline $\begin{array}{l}\text { H. latispatha X } H \text {. } \\
\text { bourgaeana }\end{array}$ & ANDERSSON (1992) & & \\
\hline $\begin{array}{l}\text { H. sarapiquensis } \mathrm{X} H \text {. } \\
\text { undulata }\end{array}$ & ANDERSSON (1992) & & \\
\hline $\begin{array}{l}\text { H. spathocircinata } \mathrm{X} H \text {. } \\
\text { psittacorum }\end{array}$ & ANDERSSON (1992) & & $\begin{array}{l}\text { Alan Carle; Golden Torch; Adrian; } \\
\text { Yellow Parrot }\end{array}$ \\
\hline H. caribaea X H. bihai & CASTRO (1995) & & $\begin{array}{l}\text { Big Red; Hot Rio Nites; Caribbean } \\
\text { Sunset 1; Carib Flame; Criswish; } \\
\text { Grand Etang; Granny Smith; Green } \\
\text { Thumb; Grenadier; Jacquinii; } \\
\text { Kawauchi; Manoa Midnight; Orange } \\
\text { Delight; Richmond Red; Vermellion } \\
\text { Lake; Yellow Dolly; Yamakawa } \\
\text { Chocolate; St. Vincent Royal; Mount } \\
\text { Hope Red }\end{array}$ \\
\hline H. episcopalis X H. standleyi & CASTRO (1995) & & \\
\hline $\begin{array}{l}\text { H. psittacorum X } H \text {. } \\
\text { marginata }\end{array}$ & CASTRO (1995) & & \\
\hline H. bihai X H. spathocircinata & CASTRO (1995) & & Cinamon Twist \\
\hline
\end{tabular}

